Article

\title{
Two-Stage Optimization Model for Life Cycle Maintenance Scheduling of Bridge Infrastructure
}

\author{
Shu-Shun Liu ${ }^{1,2, *}$, Hsin-Yi Huang ${ }^{2}$ and Nevy Risna Dyah Kumala ${ }^{1}$ \\ 1 Department of Civil and Construction Engineering, National Yunlin University of Science and Technology, \\ Yunlin 640, Taiwan; m10816024@gemail.yuntech.edu.tw \\ 2 Smart Construction Management Consulting Center, National Yunlin University of Science and Technology, \\ Yunlin 640, Taiwan; n6896115@gmail.com \\ * Correspondence: liuss@yuntech.edu.tw; Tel.: +88-6-928-512-520
}

Received: 24 November 2020; Accepted: 11 December 2020; Published: 12 December 2020

check for updates

\begin{abstract}
As bridge infrastructure ages, the deterioration of materials and hazard events reduce the service quality and compromise the safety of the structure. Therefore, there is a tremendous need for bridge maintenance planning, and such maintenance studies during recent years have focused on the life cycle aspect. To fulfill the budget requirements of life cycle maintenance, an important issue is to ensure that the limited maintenance budget is utilized in an effective way. However, there are few studies that have aimed to assess the topic of budget allocation and the adjustment of bridge life-cycle maintenance issues. In order to resolve such issues, a two-stage optimization model based on constraint programming $(\mathrm{CP})$ is proposed in this study to deal with maintenance scheduling problems. This is facilitated by adopting the resource-constrained project scheduling problem (RCPSP) framework, in which, three plans according to the maintenance time point are considered (i.e., early, middle, and late plans). According to the RCPSP concepts, this study views the budget ceiling as the resource limit, and maintenance plans as activities, so that the feasibility of each maintenance plan depends on the sufficiency of the budget. As the first stage, Model-I (the life cycle lifespan evaluation model) takes a life cycle perspective, evaluating how long it will take to keep all bridges in a serviceable condition with minimum expenditure over the planning cycle, and evaluates the annual budgets that can be used as a reference for users to draft a budget plan. Based on the planning result from Model-I and the actual annual budget approved for the current year, the second stage, Model-II (the annual budget allocation model) then reallocates the actual budget to take into account the importance of all bridges and different costs and benefits of maintenance plans, and revises the suggested annual budget values obtained by Model-I for the following years. Through a case study, the optimized result demonstrates that annual recursive implementation of this two-stage model satisfies the need to adjust existing budgetary data, and provides management personnel with optimized and realistic maintenance decision support for bridge infrastructure.
\end{abstract}

Keywords: life cycle; maintenance scheduling; budget allocation; constraint programming; bridge infrastructure

\section{Introduction}

With the aging of a bridge, the deterioration of materials and downgrading service level, as well as natural disasters such as typhoons and earthquakes, all increase the potential for bridge damage and require frequent and routine maintenance. For preventing such disasters caused by unsafe implementation of bridge maintenance, governments invest in bridge maintenance projects every year to ensure the safety of people and property. For example, in the United States, the cost of repairing and replacing deteriorating bridges was approximated as USS 100 billion in 2010 [1]. Therefore, the cost 
optimization of bridge structure maintenance becomes an important challenge in bridge management problems [2].

In recent years, it has been theoretically assumed that the budget plan should be prepared from the life cycle perspective [3-8], where the ideal budget plan is somewhat unrealistic in terms of being applicable to the real world. However, solutions to resolve the mismatch between the planned budget and the awarded budget have been rarely discussed in previous studies related to bridge maintenance problems. Thus, with practical considerations, a crucial question arises, the question of exploring how to allocate the budget where the life cycle maintenance plan violates the current budgeting policy. Such policy only complies with the needs of short-term budget expenditure and not the assessment of concerns that apply to the long-term life cycle. Thus, there exits difficulties in budget implementation, owing to the different perspectives of budget planners and budget reviewers. In Taiwan, budgeting is prepared based on a bottom-up flow. Competent authorities (e.g., budget planners) submit proposed annual budgets to higher-level authorities (e.g., budget reviewers), according to their own current situation. Subsequently, the higher-level authorities review the submitted plans, contemplate annual expenditures holistically, and allocate limited budgets. As a result, the budget plan for the following year may not necessarily be approved, as has been the case for previous proposals regarding each facility. This may be due to insufficient funds in the current year, policy changes, and other reasons, resulting in some facilities failing to obtain funds or a sufficient budget. Budget allocation does not meet the requirements of lower-level authorities (budget recipients). Thus, they must readjust maintenance plans accordingly to achieve maximum benefits, where some plans may be evaluated through a life cycle point of view.

Despite a reasonable bridge maintenance plan based on a life cycle based analysis, the required budget can often not be fully obtained owing to the aforementioned practical circumstances, which fit into the domain of resource-constrained project scheduling problems (RCPSP) [9-12]. The RCPSP mainly focuses on a contractor's constraints in terms of resource possession and the available quantity of usable resources. Thus, an upper limit is set regarding the usage of each type of resource, and the project is then scheduled. Therefore, if each bridge requiring maintenance is regarded as a resource according to the RCPSP definitions, as long as the resource is being used continuously, the serviceable condition of all the bridges can be ensured. Thus, the concept of bridge maintenance scheduling is consistent with the goal of resolving the RCPSP. In addition, project budget limitation in RCPSP is similar to the condition of limited budget utilization caused by the present reduced maintenance budget. Therefore, this study proposes the application of the RCPSP in solving maintenance scheduling problems for bridges under budget constraints.

To aid problem solving, two-stage optimization models are presented in this paper. IBM ILOG CPLEX Optimizer software and the constraint programming (CP) approach is adopted for model development [13]. In the life cycle lifespan evaluation model (Model-I), the maintenance actions for all bridges under the supervising unit has been planned, based on a life cycle perspective, to obtain the longest operation time while ensuring the serviceable condition of all the bridges. This can be helpful for bridge managers while drafting maintenance budget proposals. After the proposal is approved, according to the actual budget awarded, Model-II (the annual budget allocation model), then reallocates the actual budget to take into account the importance of all bridges and the different costs and benefits of maintenance plans. In this stage, the recalculation of life cycle maintenance scheduling is conducted to adjust the overall maintenance plan. This two-stage optimization model implemented recursively can effectively help bridge managers to solve maintenance scheduling problems for which their maintenance units are responsible.

The following sections are organized as follows. First, a literature review on infrastructure maintenance, CP applications, and RCPSP areas related to this study is briefly provided. Then, the methodology introduces how to apply the RCPSP framework in order to solve life cycle maintenance scheduling problems in relation to bridge infrastructure. The two-stage models proposed 
in this paper are then developed. Bridge infrastructure located in southern Taiwan is further used as case study to demonstrate the applicability of the proposed model. Finally, conclusions are presented.

\section{Literature Review}

Facility maintenance is an important issue for the safety of people and government finance. Maintenance must be carried out immediately at a fast-deteriorating facility as the deterioration rate will reduce the service life span $[3,14,15]$. Infrastructure can be used optimally if it is supported by economical and efficient maintenance [16,17]. A great deal of research focuses on this issue. Srinivasan and Parlikad [18] utilized a partially observable Markov decision process to capture the condition of infrastructure assets and provide a mechanism to monitor asset condition value. Stajano et al. [19] investigated wireless sensors, network applications, and the implementation of data visualization in large civil engineering infrastructure monitoring and discussed various problems and solutions. Liden and Joborn [20] introduced a regime called maintenance windows, which is used in the Swedish Transport Administration to provide a framework that can smooth the impacts on railway traffic while executing maintenance actions. Lu and et al. [21] categorized common field measuring instruments for scoring bridge conditions, and highlighted the benefits and shortcomings of such instruments to validate bridge safety assessments. Feng et al. [22] introduced nature frequency as an index to monitor bridge safety. These studies aimed at monitoring the facilities and providing a real time warning to avoid property loss from failure of the facility. A bridge serves as a guarantor for transportation between two places. Not only a suitable monitoring system, but also a reasonable maintenance plan, which corresponds to the government's annual budget preparation is needed. In annual budget preparations, maintenance costs are wasted when the preventive maintenance is inefficient $[4,5]$. The government public sector has a limited annual budget that is always insufficient to serve the needs of routine maintenance [23,24]. Alberto et al. [25] and Xie and Zhang [26] considered these maintenance budget limitations to reduce the bridge maintenance cost ratio, in order to optimize structure safety from earthquake events. Orcesi and Frangopol [27] proposed a model to optimize the maintenance strategies based on structural health monitoring information on highway bridges, which considers the maintenance cost and monitor cost. Ghodoosi et al. [2] used a genetic algorithm to develop a rational method in which deterioration, intervention effects, and financial models are considered.

Moreover, the bridge element deterioration model plays an important role in the planning model. There are two types of deterioration model, as follows: (1) Progressive deterioration affects the structure capacity continuously at a slow rate that may change randomly over time, and (2) Shock-based deterioration generates significant changes on the structure caused by extraordinary events such as natural disasters [28]. The deterioration model adopted in this study is the progressive deterioration model. Ghodoosi et al. [29] also presented a reliability deterioration model at the system level for conventional bridges, and this model can be adopted through a new reliability index. Garavaglia and Sgambi [30] proposed the Markovian renewal process as a deterioration law for maintenance strategies for a steel bridge, and a Monte Carlo methodology was finally suggested to evaluate the structural health. Saydam and Frangopol [6] utilized Markov chains to evaluate the performance of deteriorated components of composite bridge superstructures that are composed of five steel girders and reinforced concrete decks. Furthermore, Wu et al. [31] employed semi-Markov chains to create a bridge structure deterioration model based on the Federal Highway Administration (FHWA) condition ratings. Later, Fang and Sun [7] proposed a Weibull distribution based semi-Markov process model for urban bridge deterioration prediction and concluded that their model can predict the deterioration behavior of bridge infrastructure with a higher accuracy rate than existing regression analysis methods. Yang et al. [32] proposed a deterioration model for bridge structures based on a probabilistic method using Monte Carlo simulations, with Latin hypercube sampling. Choi et al. [33] introduced a performance degradation model, using a deep-learning algorithm called the long short-term memory (LSTM) algorithm—a representative recurrent neural network model—to employ bridge concrete deck inspection data which have been recorded in bridge management systems in 
Korea from 1995 up to 2017. The authors also suggested the model can be used in bridge inspection, maintenance and repair cycles, and for estimation of the inspection cost. Derived from the interaction between different defect mechanisms, Calvert et al. [34] developed a bridge structure deterioration model employing a dynamic Bayesian network.

Besides the maintenance costs, researchers are also aware of other environmental factors when constructing a maintenance plan. Orcesi and Cremona [35] developed a framework for bridge maintenance problems which considers user cost, bridge owner cost, and the specific location of each bridge in the transportation network. Thompson and et al. [36] proposed the user cost model of bridges with three considerations, which are (1) bridge widening affects accident risk, (2) bridge strengthening affects the ability of heavy trucks to pass and so consideration must be given to the detour costs, and (3) bridge raising affects the ability of tall trucks to pass under the bridge. Although this paper is not aimed at bridge maintenance, these concepts in terms of user cost, especially occur when a bridge is in the maintenance period. Huang and Huang [37] considered reducing user cost when a bridge in maintenance and provide a bridge maintenance plan model which aims to discuss applicable maintenance schedules of various bridge components. Hu et al. [38] intended to reduce user cost based on traveling distance within a bridge network, from the perspective of waiting time. Lwambuka and Mtenga [8] attempted to reduce the user cost that is caused by bridge maintenance. Therefore, most of the studies are from the perspective of life cycle, and take structural health in terms of deterioration into consideration. Frangopol and Soliman [39] provided an overview in the field of life cycle engineering for civil and marine structural systems, as well as future research directions.

Constraint programming $(\mathrm{CP})$ is a computer implementation integrated $\mathrm{AI}$ (artificial intelligence) and OR (operations research) technique [40,41]. It has been adopted to solve many combinatorial problems in different fields. For example, Liu and Wang [42] proposed a new linear scheduling model for construction sites which allows for consideration of a multi-skill work crew with high productivity and great work continuity, and it adopts a CP optimization process to solve linear scheduling problems. Meng et al. [43] and Lunardi et al. [44] performed a comparison between $\mathrm{CP}$ and mixed-integer linear programming to minimize the make-span in a shop scheduling problem. Pour et al. [45] combined hybrid approaches of constraint programming and mixed-integer programming to develop an initial feasible solution-the "warm start" solution. This model was applied in the Danish railway system and produced significant initial solutions for solving large-scale scheduling problems. Moreover, Hauder et al. [46] also adopted a combination of mixed-integer and CP methods to consolidate flexible project scheduling problems. Wallace and Smith [47] created a new constraint programming model to solve the cyclic hoist scheduling problem, which was proven to be more effective than the previous CP-based models. Hojabri et al. [48] developed a CP-based adaptive neighborhood search model to solve vehicle routing problems dealing with the logistical issues of large items for retailer companies, where the solution focuses on the synchronization of arrival times of delivering items and the crew for installation in customer sites. Kizilay and et al. [49] proposed CP models to solve he integrated port container terminal problem (IPCTP) that considers the optimization of the intersectional operations quay and yard crane assignments and scheduling, yard location selection, and yard truck assignment and scheduling. For maintenance issues, Lazarev and et al. [50] proposed an optimization algorithm for locomotive maintenance scheduling. Different objectives were discussed in this research. Such objectives include the minimization of several important time-related variables, such as total and average waiting times of locomotives, and the start and finish time of maintenance on all locomotives. Compared with the heuristic algorithm, CP with the ILOG CPLEX Optimizer provides better results in less time.

On the other hand, resource limitation is another issue to consider and has great influence on optimization problems in various fields. In construction sites, resource allocation issues are crucial to a project's success, since the available resources are always less than the required resources. In the proposed two-stage optimization model, the bridge maintenance problem is treated as the special case in the resource-constrained project scheduling problem (RCPSP). RCPSP is a problem domain 
used to search for the optimal solution in terms of project schedules, in order to minimize the project's duration based on resource limitations and precedence constraints [9]. RCPSP became a challenging problem for project managers based on project characteristics, such as different types of activities, massive resource usage, and complex precedence relationships $[10,11]$. On the other hand, the main reason for project delays is a lack of proper resource-constrained scheduling [12]. In a resource-constrained environment, typical time-cost trade-off analyses are discussed, and moreover, the overall evaluations of project performance in regard to quality and environmental impacts should be further considered [51,52]. The RCPSP framework was adopted to solve scheduling problems in project management, manufacturing planning, and construction management. Several RCPSP applications in the construction management field have been conducted in the last decade. Liu and Wang [53] proposed a CP-based optimization model which aims to integrate RCPSP and cash flow problems, where typical calculations of cash flows usually ignore resource usage. This model was developed from a contractor's point of view and attempted to tackle the management goal of profit maximization. Goncalves et al. [54] used a genetic algorithm (GA) to solve the resource constrained multi-project scheduling problem (RCMPSP). The goal is to find a schedule of the activities (i.e., to determine the start and completion times of the detailed activities). It takes into consideration multi-resource and inter-project precedence constraints, and the objective function is overall project duration minimization. Several alternative solutions representing different decoding methods were tested with different sizes of projects from 10 to 50 projects, where activity number varies from 1200 to 6000 activities. $\mathrm{Hu}$ and Flood [55] also adopted a GA to solve RCPSPs with the consideration of two objectives: minimization of the project's overall duration and total cost. The strength Pareto evolutionary approach II (SPEA II) was assessed with a proposed innovative chromosome design. In the past decade, research of RCPSP has utilized many metaheuristics methods, such as particle swarm optimization (PSO), genetic algorithm (GA), ant colony optimization (ACO), and simulated annealing (SA). However, none of these methods can well perform in all situations [56].

\section{Methodology}

\subsection{Constraint Satisfaction Problem}

The concept of constraint programming can be traced back to the 1970s when academics in the artificial intelligence field first studied the constraint satisfaction problem (CSP) [57]. The range of values for every variable when all constraints are satisfied determines the feasible region of the problem and is the key to solving the CSP, according to the discussions of typical research institutes. There are many different solutions, of which, two are commonly used. These are the consistency and branch and bound techniques, which can be used in combination [58,59]. The consistency technique comprises two stages. The first stage is the domain reduction stage, which involves eliminating values that do not satisfy the constraints considering the variable range and modifying the number of variable domains; the second stage is the constraint propagation, which involves propagating the domain change of a variable to constraints relevant to the variable. When a variable is modified, the constraints update the range of values, and newly added domain constraints are propagated to the original constraint. This process removes all the variable ranges that do not satisfy the constraints and continues until all the values in the variable domain satisfy every constraint [59]. In the branch and bound method, nodes in the tree represent variables, each of which is branched according to the number of domains of the variable. The solutions generated are tested individually according to the branching order. When there are no feasible solutions, the previous branching layer of the variable is selected and the branch searching process is conducted for other variables until a feasible solution is found. The forward checking algorithm comprises the consistency technique and the branch and bound method. It focuses on performing the branch and cut technique. When a domain is branching a specific variable, the consistency technique is immediately applied to check the domains of other variables at each branch, and the infeasible domains are eliminated according to the constraints, significantly 
reducing the number of branches of the subsequent variables, thus enhancing the efficiency in finding a solution [60].

\subsection{Bridge Maintenance Strategy and RCPSP}

This section describes the whole idea regarding the bridge maintenance activity with project scheduling. To illustrate the entire concept in detail, basic definitions relevant to the RCPSP are elaborated as follows:

- Activity: a plan refers to the process of implementing maintenance methods on any bridge parts at any point in time within a period and achieving the maintenance benefits in a given duration. The ACTIVITY in the RCPSP has been referred to as a maintenance plan for this study.

- Duration: when a maintenance plan is selected, the maintenance effects for the targeted bridge will last for a different period in each case. This period corresponds to the activity DURATION defined in the RCPSP.

- Cost: the maintenance cost of each plan can be referred to as the COST of each activity in the RCPSP. This derived maintenance cost will be expressed as an annual value at each time point in this study. In each plan, an equal amount of the maintenance budget must be expended at each time point. Taking "year" as the unit in the calculation method also conforms to the style adopted by the government in compiling budgets each year.

- Facility Resource: the subject matter of this study—bridge components-is also regarded as the FACILITY RESOURCE item in the RCPSP. That is, an activity requires resources for execution. When the activity is in the execution status, the facility resource is used. Similarly, when the facility resource is in use, the bridge can still function.

Based on the above definitions, to explain the scope and limitations of model applicability, some assumptions are made, as follows:

1. The maintenance plans for each bridge are evaluated in terms of the cost and the functional period after the maintenance is completed.

2. When a maintenance plan is completed, the corresponding bridge is safe and functional within the aforementioned period (i.e., endurance time).

3. Based on experience, unless a bridge suffers from major damage, it is rarely in an unusable condition. Even when maintenance work is being carried out, the bridge will still have a certain degree of usability. Therefore, in this study, the bridge examined is considered to be usable during the maintenance period. The functional period includes the maintenance period and the effect period and corresponds to the duration of the RCPSP.

4. Through intensive expert reviews, we found out that the maintenance information for some bridges was not completely preserved, for example the detailed cost and the maintenance period. Therefore, some parameters used in this study, such as the effect period and year remaining of the effect period, were based on assessments provided by the maintenance unit, and reasonable assumptions were made.

5. The major contribution of this study is to provide a budget allocation and adjustment mechanism for maintenance scheduling problems, from the perspective of life cycle routine maintenance. As the statement of assumption three explains, all facilities still have a certain degree of usability above the minimal acceptable condition. Though major disaster impacts to bridges, such as earthquakes and typhoons, may be the crucial factors for bridge failures, post-disaster emergency repairs and rehabilitation are not considered in this study due to budgeting issues in such emergence repair projects related to special funding, not included in the category of the annual budgeting discussed in this study.

The relationship between the bridge maintenance budget allocation and RCPSP framework is listed in Table 1. 
Table 1. Relationship between bridge maintenance and resource-constrained project scheduling problem (RCPSP) framework.

\begin{tabular}{cc}
\hline RCPSP & Bridge Maintenance in This Study \\
\hline Activity & Plan \\
\hline Duration & Functional period \\
\hline Cost & Maintenance cost \\
\hline Facility Resource & Bridge component \\
\hline
\end{tabular}

\section{Model Description}

In this study, the concept of RCPSP is used to find a proper plan for bridge maintenance. A one-time maintenance strategy of the bridge and its effectiveness are shown in Figure 1.

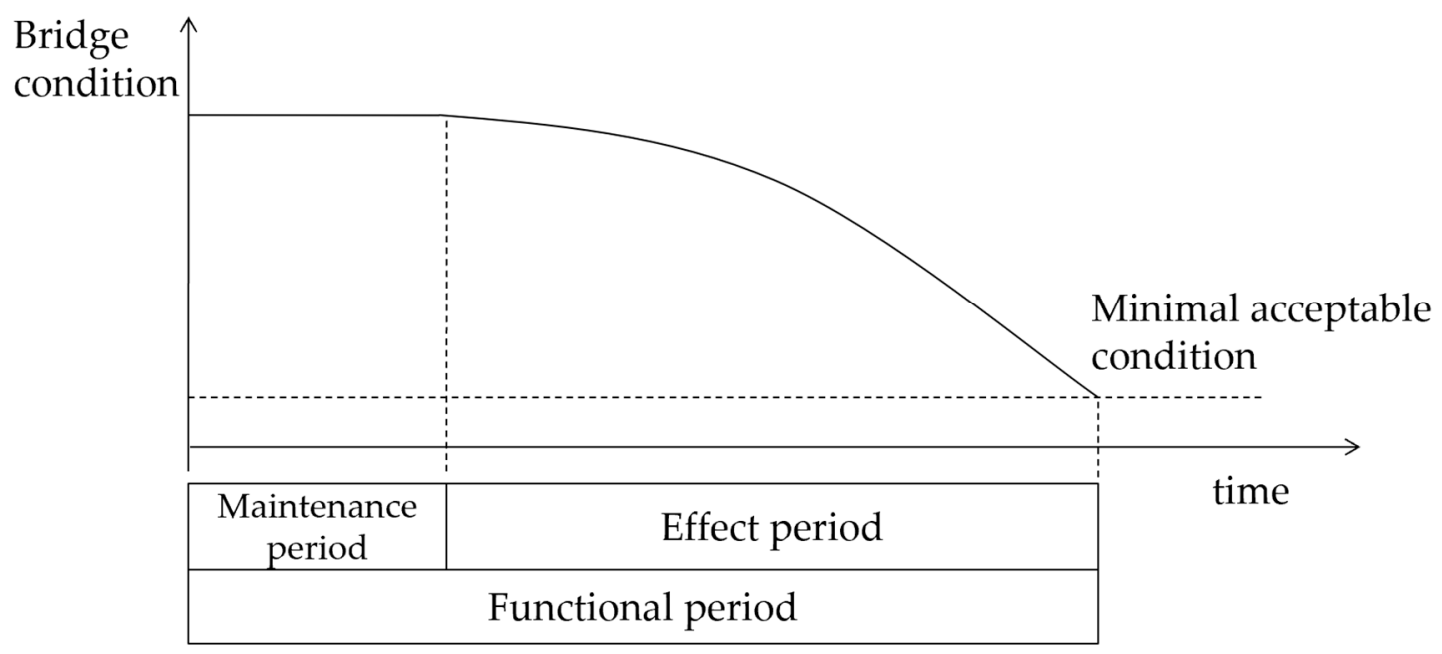

Figure 1. Illustration of bridge maintenance effect.

The plan includes two periods. These are named the maintenance period and the effect period in this study. Additionally, the total period of a plan is named as the functional period in this study. Table 2 shows the parameters of the two periods corresponding to the RCPSP.

Table 2. Parameters of two periods corresponding to RCPSP.

\begin{tabular}{ccc}
\hline & \multicolumn{2}{c}{ Parameters in RCPSP } \\
\hline Plan period & Cost & Duration \\
\hline Maintenance period & Maintenance cost & Maintenance duration \\
\hline Effect period & Daily maintenance cost & $\begin{array}{c}\text { Operation duration after } \\
\text { maintenance }\end{array}$ \\
\hline
\end{tabular}

The cost incurred during the maintenance period is the construction cost, and the cost incurred during the effect period refers to the daily expenditure for maintenance operations. The overall duration (the aforementioned functional period) includes the maintenance period and the effect period.

Considering the implementation time of maintenance work, this study concludes the following points based on [32]: if a bridge is maintained earlier, the operating period can be extended more, suggesting a longer effect period; meanwhile, if the maintenance is carried out late, the effect period becomes shorter. Figure 2 elaborates on this concept, with the horizontal and vertical axes referring to the time and the condition of the bridge, respectively. The larger the vertical axis value, the better 
the bridge's condition. However, the model retains flexibility in the setting of parameters, where the parameters can be adjusted according to the actual conditions.

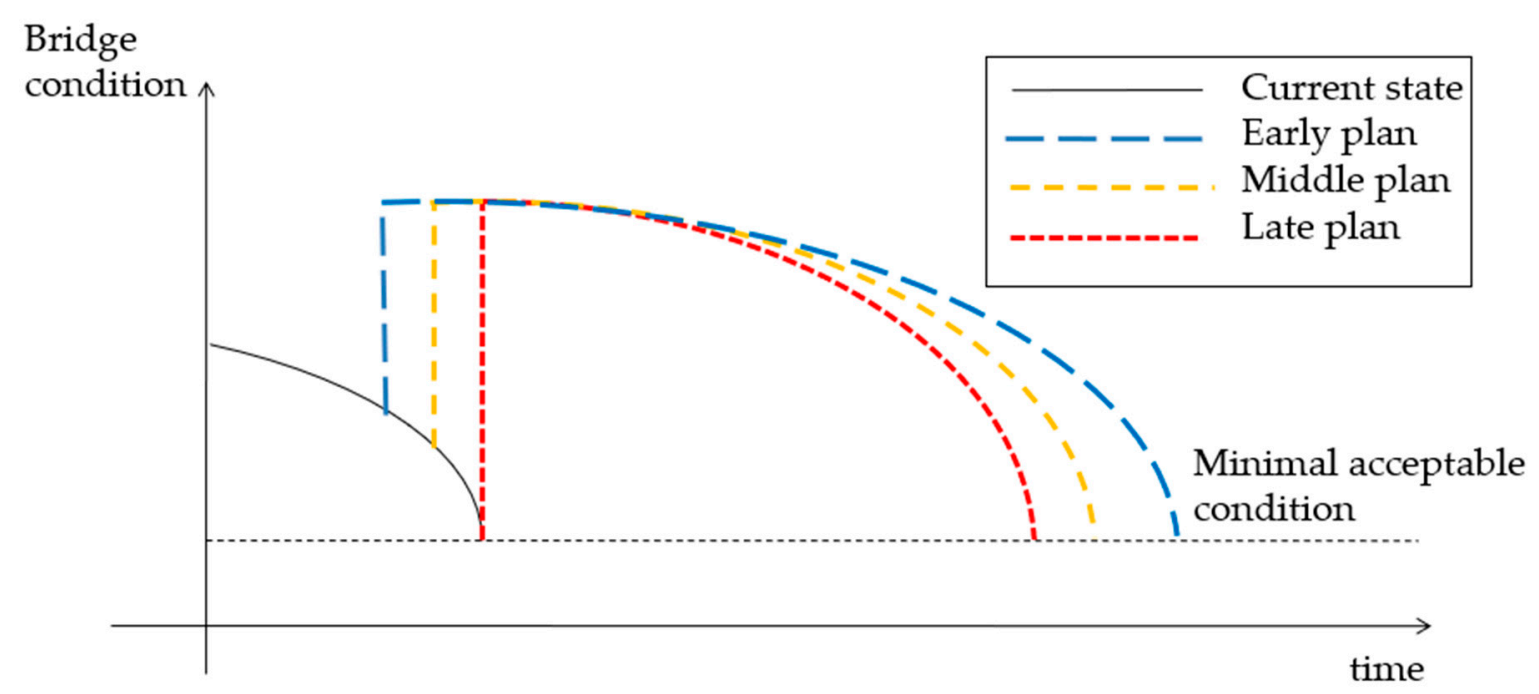

Figure 2. Diagram of different plans.

Moreover, as shown in Figure 2, this study classifies the implementation of the plan into three scenarios (i.e., early, middle, and late) and refers them as early, middle, and late plans, respectively. These plans are implemented on the bridge in its current state (i.e., early and middle plans) at three different time frames. Therefore, the selection of plans will have an impact on the remaining operation duration of the current plan of the bridge. Naturally, the earlier the plan is executed, the longer the remaining duration of the leading plan will be sacrificed. As shown in Figure 3, subsequent plans change the duration of the current plan. In general, the early plan significantly reduces the functional period of the leading plan, while the late plan does not affect it.

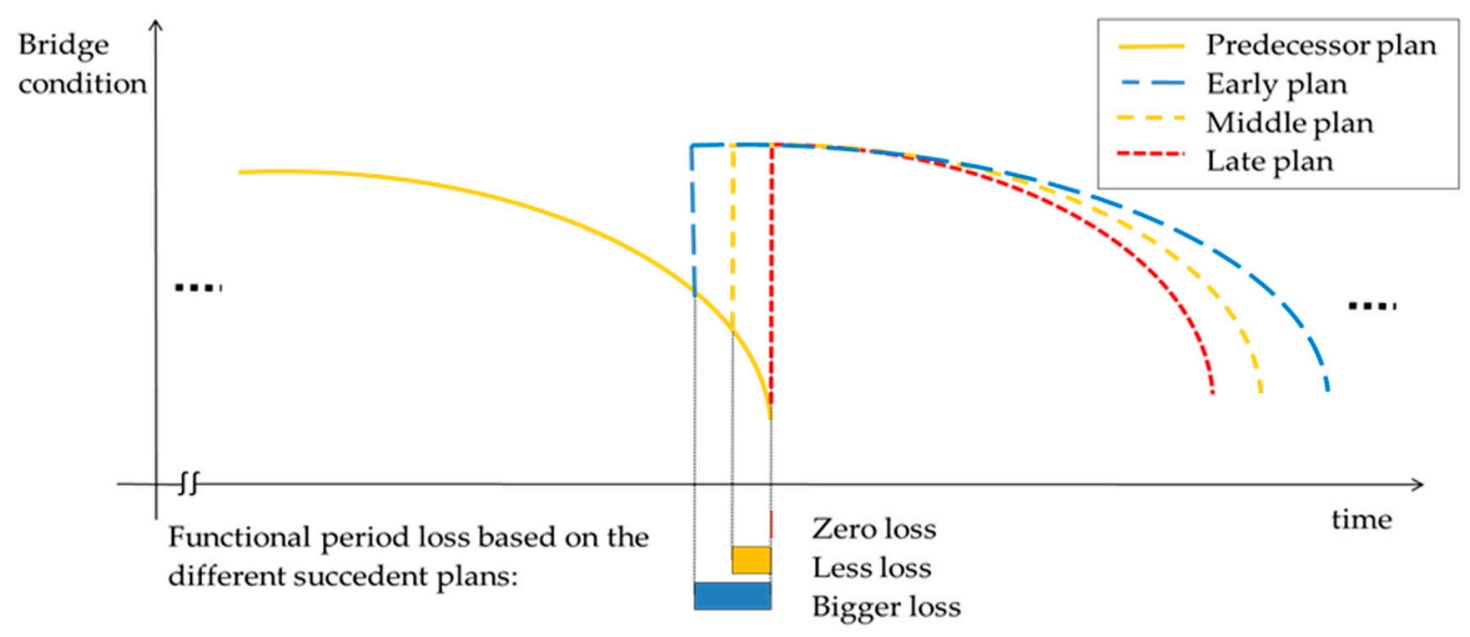

Figure 3. Impact of different plans on the leading plan.

Greater variation can be observed while reducing the functional period of the leading plan. When there are different leading programs and an early plan, a middle or late plan is selected, shown in Figure 4. 


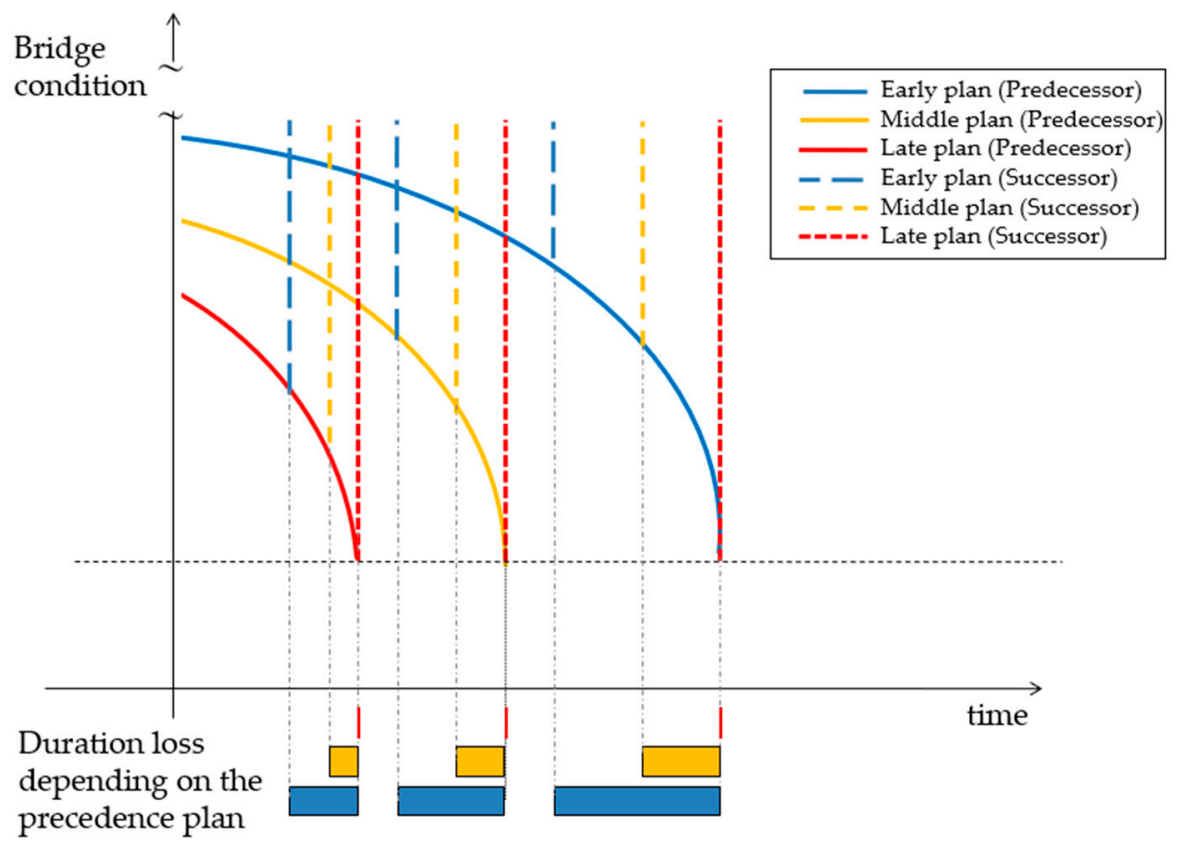

Figure 4. Impact of subsequent plans on different leading programs.

This difference can be represented by an influence matrix (Table 3). Each value in the matrix represents the amount of service life lost for each plan combination. The influence matrix can be used to find the best plan combination.

Table 3. Influence matrix.

\begin{tabular}{cccc}
\hline \multirow{2}{*}{ Predecessor } & \multicolumn{3}{c}{ Successor } \\
\cline { 2 - 4 } & Early Plan & Middle Plan & Late Plan \\
\hline Plan A & 4 & 3 & 0 \\
Plan B & 3 & 2 & 0 \\
Plan C & 2 & 1 & 0 \\
\hline
\end{tabular}

Overall, this study proposes two models according to the actual requirements. The recursive yearly implementation process is shown in Figure 5. Subordinate authorities use Model-I to evaluate the annual maintenance cost for all bridges in the planning cycle, and use the results of the model as a reference basis for utilizing the following year's budget, though the result of Model-I is calculated in a budget-free setup. Figure 6 shows a possible result computed by Model-I. Supposing there are 4 facilities and 3 plans, Model-I conducts the arrangement of maintenance plans for each facility from the life cycle perspective under a given planning time. After the actual budget is approved and issued for the specified year, the model is re-evaluated, and accordingly, bridge maintenance works are carried out using Model-II. Finally, adjustments are made according to the actual situation, such as modifications to the importance of the remaining bridges to be maintained, and the updated data are entered into the life cycle assessment model to re-evaluate and minimize the impact of the budget gap on the overall life cycle of the bridges. Figure 7 displays a possible result solved by Model-II. In Figure 7, facility 1 and 3 have a year remaining of their effect periods and so an early maintenance event may occur within the period. However, facilities at the end of the effect period (i.e., facilities 2 and 4) require maintenance. 


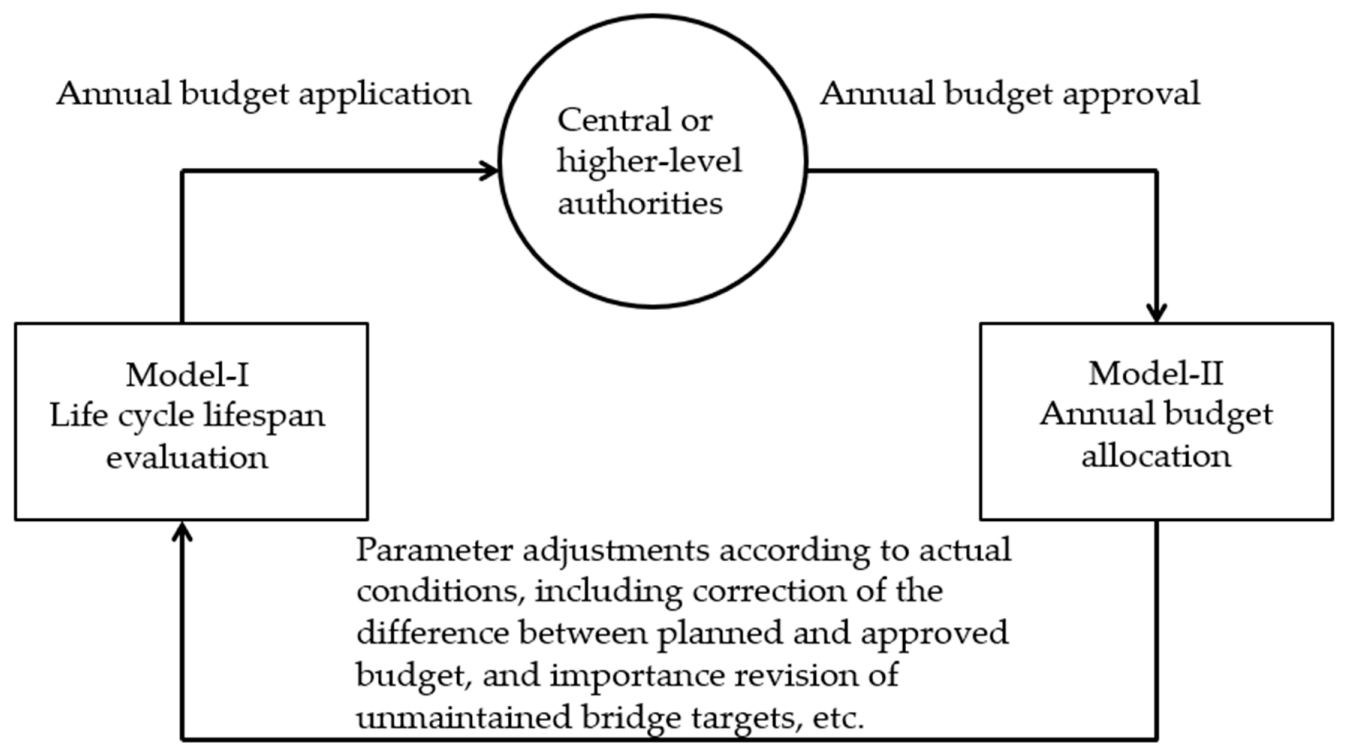

Figure 5. Annual recursive implementation process of two models.

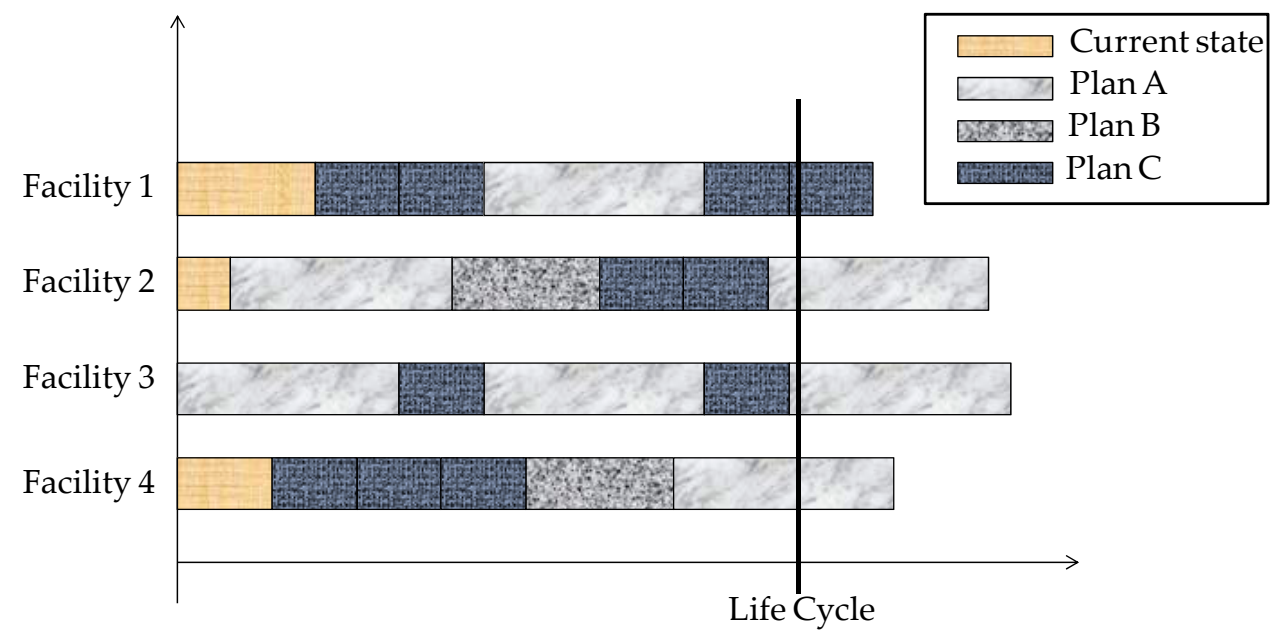

Figure 6. Possible result of Model-I.

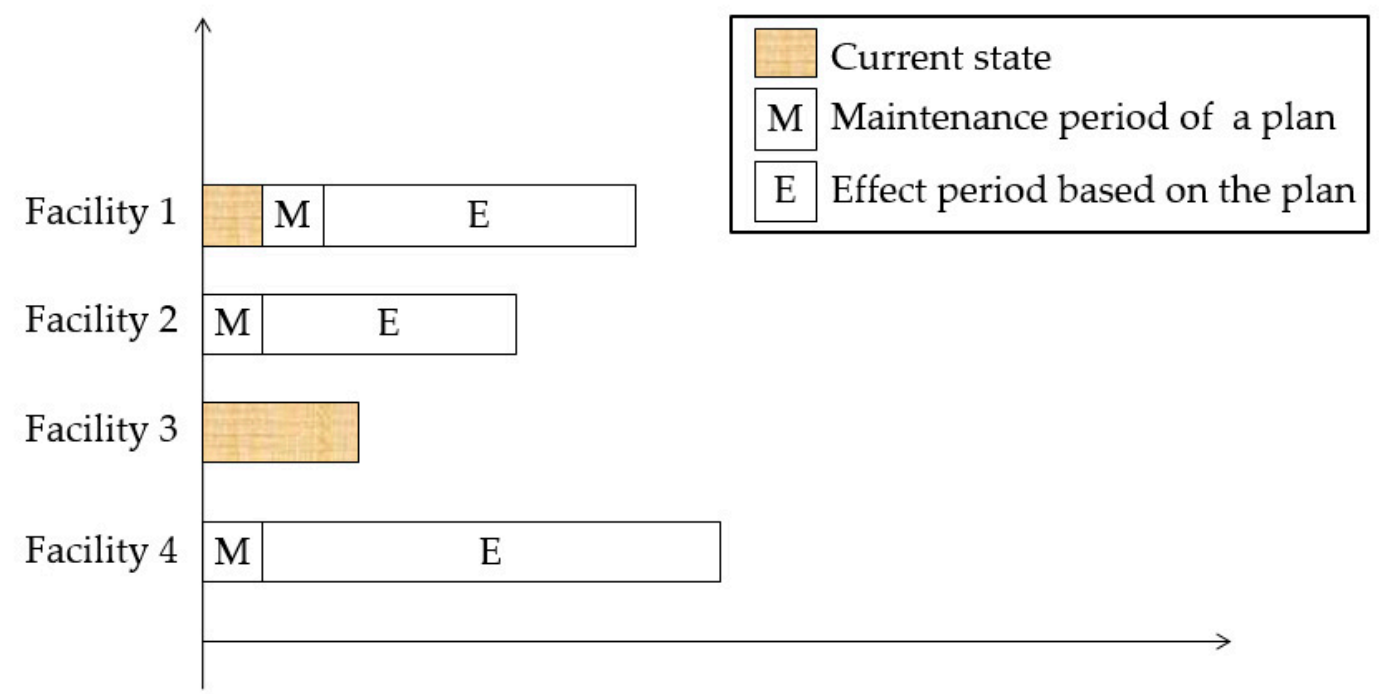

Figure 7. Possible result of Model-II. 


\subsection{Model-I: Life Cycle Lifespan Evaluation Model}

All model parameters and variables are shown in Table 4. To solve the long-term maintenance budget allocation problem, Model-I maximizes the functional periods of all bridges from the perspective of life cycle under a given planning time. Therefore, through the concept of limited resource scheduling, the related constraints are described as follows:

$$
\forall_{i, j, k}\left(M S_{i j k}=B S_{i j k}+B D_{i j k}\right)
$$

Table 4. Model parameters and variables.

\begin{tabular}{|c|c|}
\hline Parameter & Statement \\
\hline$f$ & Total number of considered bridges \\
\hline$r$ & Total number of considered bridge components \\
\hline$t$ & Total number of plans \\
\hline$c$ & Number of plan cycles in a life cycle \\
\hline$q$ & Number of years in a life cycle \\
\hline$i$ & Bridge number, where $\mathrm{i}=1,2,3, \ldots, \mathrm{f}$ \\
\hline$j$ & Bridge component number, where, $\mathrm{j}=1,2,3, \ldots, \mathrm{r}$ \\
\hline$k$ & Plan cycle number, where $\mathrm{k}=1,2,3, \ldots, \mathrm{c}$ \\
\hline$p$ & Plan selection, where $\mathrm{p}=1,2,3, \ldots, \mathrm{t}$, for example, early/middle/late \\
\hline$u$ & Year number, where $\mathrm{u}=1,2,3, \ldots, \mathrm{q}$ \\
\hline$m$ & Current plan selection, where $\mathrm{m}=1,2,3, \ldots, \mathrm{t}$, for example, early/middle/late \\
\hline$w_{i}$ & Weight of bridge i \\
\hline$b d_{i j p}$ & A plan's maintenance period for a facility (i.e., bridge component) \\
\hline$m d_{i j p}$ & A plan's effect period for a facility \\
\hline$p b d_{i j}$ & Facility maintenance period in the current plan \\
\hline$p m d_{i j}$ & Facility effect period in the current plan \\
\hline$r u l_{i j k u}$ & Resource limit in a year \\
\hline$b u c_{i j p}$ & Facility maintenance cost of a plan \\
\hline$m u c_{i j p}$ & Facility effect period cost per year \\
\hline bur $r_{i j p}$ & Possible maintenance period of the plan for each facility \\
\hline mur $_{i j p}$ & Possible effect period of the plan for each facility \\
\hline $\mathrm{cul}_{u}$ & Budget limit in year $u$ \\
\hline Variable & Statement \\
\hline$B D_{i j k}$ & Maintenance period for a facility (component $j$ of bridge $i$ in plan cycle $k$ ) \\
\hline$M D_{i j k}$ & Effect period for a facility (component $j$ of bridge $i$ in plan cycle $k$ ) \\
\hline$B S_{i j k}$ & Start time of a plan's maintenance period (component $j$ of bridge $i$ in plan cycle $k$ ) \\
\hline$M S_{i j k}$ & Start time of a plan's effect period (component $j$ of bridge $i$ in plan cycle $k$ ) \\
\hline$B F_{i j k}$ & End time of a plan's maintenance period (component $j$ of bridge $i$ in plan cycle $k$ ) \\
\hline$M F_{i j k}$ & End time of a plan's effect period (component $j$ of bridge $i$ in plan cycle $k$ ) \\
\hline$P B D_{i j}$ & Maintenance period for a facility in the current state (component $j$ of bridge $i$ ) \\
\hline$P M D_{i j}$ & Effect period for a facility in the current state (component $j$ of bridge $i$ ) \\
\hline$P B S_{i j}$ & Start time of maintenance period for a facility in the current state (component $j$ of bridge $i$ ) \\
\hline$P M S_{i j}$ & Start time of effect period for a facility in the current state (component $j$ of bridge $i$ ) \\
\hline$P B F_{i j}$ & End time of maintenance period for a facility in the current state (component $j$ of bridge $i$ ) \\
\hline$P M F_{i j}$ & End time of effect period for a facility in the current state (component $j$ of bridge $i$ ) \\
\hline$B S S_{i j p}$ & $\begin{array}{l}\text { Start time of a plan's maintenance period for Model-II (component } j \text { of bridge } i \text { with plan } \\
\text { selection } p \text { ) }\end{array}$ \\
\hline$M_{S S} S_{i j p}$ & Start time of a plan's effect period for Model-II (component $j$ of bridge $i$ with plan selection $p$ ) \\
\hline$R U B_{i j k u}$ & $\begin{array}{c}\text { Use of resources when a bridge component is in the maintenance period (component } j \text { of } \\
\text { bridge } i \text { in plan cycle } k \text { in year } u \text { ) }\end{array}$ \\
\hline$R U M_{i j k u}$ & $\begin{array}{l}\text { Use of resources when a bridge component is in the effect period (component } j \text { of bridge } i \text { in } \\
\text { plan cycle } k \text { in year } u \text { ) }\end{array}$ \\
\hline$T U_{i j k}$ & Plan choice (component $j$ of bridge $i$ in plan cycle $k$ ) \\
\hline$P T U_{i j k}$ & Current plan (component $j$ of bridge $i$ in plan cycle $k$ ) \\
\hline
\end{tabular}


Table 4. Cont.

\begin{tabular}{cc}
\hline Parameter & Statement \\
\hline$D C_{i j p m}$ & Duration in the Influence Matrix (component $j$ of bridge $i$ to plan selection $p$ from current plan \\
selection $m$ )
\end{tabular}

Formula (1) indicates the starting time at which any plan enters the effect period upon maintenance completion, thus ensuring the above definition that a plan must consist of two periods, i.e., the maintenance and effect periods.

$$
\forall_{i, j, k}\left(B S_{i j, k+1}=M S_{i j k}+M D_{i j k}\right)
$$

Formula (2) indicates that the starting time of the next plan is equal to the end of the defined service life of the previous plan, thus confirming that the plans need to be continuous and uninterrupted in the time series.

$$
\forall_{i, j}\left(M F_{\mathrm{ijc}} \geq q\right) \text { for } k=c
$$

Formula (3) ensures the solution meets the defined considered years.

$$
\begin{aligned}
& \text { if } \forall_{i, j, k}\left(T U_{i j, k-1}=p\right) \&\left(T U_{i j k}=m\right) \\
& \text { then } \forall_{i, j, k, p, m}\left(M D_{i j, k-1} \leq M D_{i j, k-1}-D C_{i j p m}\right) \\
& i=1 \sim f, j=1 \sim r, k=2 \sim c, p=1 \sim t, m=1 \sim t
\end{aligned}
$$

Formula (4) indicates that the effect period for a bridge is defined after the selection of the current and subsequent operation plans. $D C_{i j p m}$ is the influence parameter and its values are shown in Table 3 .

$$
\begin{aligned}
& \text { if } \forall_{i, j, k}\left(T U_{i j k}=p\right) \\
& \text { then } \forall_{i, j, k}\left(B D_{i j k}=\operatorname{bd}_{i j P}\right) \text { and }\left(M D_{i j k} \leq m d_{i j P}\right)
\end{aligned}
$$

Formula (5) indicates that when a plan $p$ is selected, its maintenance period and service life are also defined.

$$
\sum_{u=1}^{q} \sum_{k=1}^{c} \sum_{j=1}^{r} \sum_{i=1}^{f}\left(r u l_{i j k u}\right) \geq \sum_{u=1}^{q} \sum_{k=1}^{c} \sum_{j=1}^{r} \sum_{i=1}^{f}\left(R U B_{i j k u}+R U M_{i j k u}\right)
$$

Formula (6) sets the upper limit of resource usage. The resources here, refer to bridges, so that each facility in use (i.e., a facility undergoing a maintenance plan) cannot be used by another plan. This ensures that the plans will not be repeated at the same time.

$$
\forall_{i, j}\left(P B S_{i j}\right)=0
$$

Formula (7) indicates that the start time for the current maintenance activity must be 0 , regardless of whether the plan is implemented in the maintenance period or in the effect period, the current operation must be controlled at the onset of the planning period. If the bridge is being constructed using a maintenance plan, the model will enter the maintenance period of the plan. If the plan has 
been implemented and is in the effect period, the maintenance duration is 0 and the remaining effect period is entered.

$$
\forall_{i, j}\left(P B F_{i j}=P M S_{i j}\right)
$$

Formula (8) ensures that the end of the maintenance periods of all bridges equals to the beginning of their effect periods.

$$
\forall_{i, j}\left(P M F_{i j}=B S_{i j, 1}\right) i=1 \sim f, j=1 \sim r, k=1
$$

Formula (9) indicates the end time of the current effect period, which is equal to the start time of the first plan.

$$
\forall_{i, j}\left(P B D_{i j}=p b d_{i j}\right)
$$

Formula (10) indicates that the current maintenance period parameter $p b d_{i j}$ in the model is entered as the input into the current maintenance period variable $P B D_{i j}$. Its value is more than 0 during maintenance, and 0 after maintenance.

$$
\forall_{i, j}\left(P M D_{i j} \leq p m d_{i j}\right)
$$

The remaining effect period of the current operation must also be entered as the input parameter into the model. Formula (11) indicates that the remaining time parameter $p m d_{i j}$ in the model is entered as the input into the current remaining effect period variable $P M D_{i j}$. However, since the remaining effect period may vary due to the selection of subsequent plans, $P M D_{i j}$ is less than or equal to $p m d_{i j}$

$$
\begin{gathered}
\text { if } \forall_{i, j, k}\left(P T U_{i j k}=p\right) \& \forall_{i, j, k}\left(T U_{i j k}=m\right) \\
\text { then } \forall_{i, j} P B D_{i j} \leq P M D_{i j}-D C_{i j P M} \\
i=1 \sim f, j=1 \sim r, k=1, p=1 \sim t, m=1 \sim t
\end{gathered}
$$

As mentioned above, the current remaining effect period will also vary depending on the choice of subsequent plans. Formula (12) indicates that when the current usage plan and the subsequently selected plan are determined, the current remaining effect period variable $P M D_{i j}$ will be deducted according to the value determined by the plan maintenance impact variable $D C_{i j p m}$, to obtain the final current remaining effect period.

The objective function is shown in Formula (13). According to the actual demand, the budget ceiling for the whole plan cycle is not considered. The objective function is "to maximize the operating time under the condition that all facilities must be in their effect period throughout the plan cycle". In addition, the importance of maintenance for the different facilities is determined by a weight, $w_{i}$, that represents the relative importance of each bridge, which can be appropriately set by the managing personnel. The larger the wi value, the more important the bridge.

$$
\text { Maximize } \sum_{k=1}^{c} \sum_{j=1}^{r} \sum_{i=1}^{f}\left(w_{i} \times M D_{i j k}\right)
$$

\subsection{Model-II: Annual Budget Allocation Model}

In response to the practical situation in which the maintenance budget has been cut and re-planning is required, this study proposes Model-II, i.e., an annual budget allocation model. The related constraint equation of Model-II is described as follows:

$$
\forall_{i, j, p}\left(M S S_{i j p}=B S S_{i j p}+B D S_{i j p}\right)
$$

Formula (14) first ensures that the two periods of an operation, i.e., maintenance and effect periods, are continuous.

$$
\forall_{i, j, p}\left(B S S_{i j p}\right)=0
$$


Formula (15) sets the maintenance period of the operation and its starting time as 0.

$$
\begin{aligned}
& \text { if } \forall_{i, j, p}\left(D S_{i j p}=1\right) \\
& \text { then } \forall_{i, j, p}\left(B D S_{i j p}=b d_{i j p}\right) \\
& \&\left(B U C_{i j p}=b u c_{i j p}\right) \\
& \&\left(B U R_{i j p}=1\right)
\end{aligned}
$$

Formula (16) indicates that when a facility is maintained, the maintenance time and maintenance budget will be brought into the model calculation. $B U R_{i j p}=1$ indicates that the facility resources are being used.

$$
\begin{aligned}
& \text { if } \forall_{i, j, p}\left(D S_{i j p}=1\right) \\
& \text { then } \forall_{i, j, p}\left(M D S_{i j p}=m d_{i j p}\right) \\
& \&\left(M U C_{i j p}=m u c_{i j p}\right) \\
& \&\left(M U R_{i j p}=1\right)
\end{aligned}
$$

Formula (17) also indicates that if a certain part of a bridge has been determined to be maintained according to a certain maintenance plan, then the corresponding maintenance period, cost, and resources required for the maintenance plan to keep the facility in effect are also determined.

$$
\begin{aligned}
& \text { if } \forall_{i, j, p}\left(D S_{i j p}=0\right) \\
& \text { then } \forall_{i, j, p}\left(B D S_{i j p}=0\right) \\
& \&\left(B U C_{i j p}=0\right) \\
& \&\left(B U R_{i j p}=0\right) \\
& \text { if } \forall_{i, j, p}\left(D S_{i j p}=0\right) \\
& \text { then } \forall_{i, j, p}\left(M D S_{i j p}=0\right) \\
& \&\left(M U C_{i j p}=0\right) \\
& \&\left(M U R_{i j p}=0\right)
\end{aligned}
$$

Formulas (18) and (19) indicate that if the maintenance plan has not occurred, the cost, maintenance period, and resource usage during the maintenance and effect periods will not occur. The function of these constraint equations is that when the budget is insufficient or if the bridge requiring maintenance cannot be maintained, the corresponding parameter values will not be included into the variables.

$$
\sum_{p=1}^{t} \sum_{j=1}^{r} \sum_{i=1}^{f}\left(\text { bur }_{i j p}\right) \geq \sum_{p=1}^{t} \sum_{j=1}^{r} \sum_{i=1}^{f}\left(B U R_{i j p}\right)
$$

According to the resource constraints, the total amount of facility resources for the maintenance operation in formula (20) cannot exceed the upper limit of the original facility resources.

$$
\sum_{p=1}^{t} \sum_{j=1}^{r} \sum_{i=1}^{f}\left(\text { mur }_{i j p}\right) \geq \sum_{p=1}^{t} \sum_{j=1}^{r} \sum_{i=1}^{f}\left(M_{i} U R_{i j p}\right)
$$

Similarly, Formula (21) indicates that the total amount of facility resources for all operations, to keep the facility in the effect period, cannot exceed the upper limit of the original facility resources.

$$
\operatorname{cul}_{u} \geq \sum_{p=1}^{t} \sum_{j=1}^{r} \sum_{i=1}^{f}\left(B U C_{i j p u}+M U C_{i j p u}\right)
$$

Formula (22) indicates that the sum of the costs spent in all the maintenance and effect periods cannot exceed the budget ceiling for that year $u$. 
Under the condition that only a single year is considered, the objective function is shown in (23). In response to possible budget shortfall, the objective formula adds the variable $M U R_{i j p}$, which reflects whether facility resources are being used. If maintenance occurs, then its value is 1 , otherwise it is 0 . The usage time of the facility is added up and maximized.

$$
\text { Maximize } \sum_{p=1}^{t} \sum_{j=1}^{r} \sum_{i=1}^{f} M U R_{i j p}\left(w_{i} \times M D S_{i j p}\right)
$$

\section{Case Study}

The two-stage model proposed in this study is illustrated and verified by the following case study. The data for this case study were provided by the Dounan Maintenance Division of the Fifth District Maintenance Agency of the Directorate General of Highways, Ministry of Transportation and Communications, Taiwan. The actual maintenance information of the maintenance division, such as the number of bridges, cost, and maintenance period, was obtained through expert interviews. However, the maintenance information of some bridges was not completely preserved. Therefore, some parameters, such as the effect period, were based on the data provided by the maintenance unit, and reasonable assumptions were made. Table 5 shows the current situations of the eight bridges maintained by the unit. As shown in Table 5, this study considers the superstructure and substructure of each bridge separately. For example, the superstructure of facility one has been maintained according to plan two, and the maintenance has been completed, with a remaining effect period of 4 years.

Table 5. Current status of bridges.

\begin{tabular}{|c|c|c|c|c|c|}
\hline Facility & Current Plan & $\begin{array}{l}\text { Year Remaining of } \\
\text { Effect Period }\end{array}$ & Facility & Current Plan & $\begin{array}{l}\text { Year Remaining of } \\
\text { Effect Period }\end{array}$ \\
\hline 1(Sup) & 2 & 4 & 5(Sup) & 2 & 6 \\
\hline $1(\mathrm{Sub})$ & 2 & 6 & $5(\mathrm{Sub})$ & 3 & 0 \\
\hline 2(Sup) & 1 & 6 & 6(Sup) & 1 & 0 \\
\hline $2(\mathrm{Sub})$ & 2 & 4 & $6(\mathrm{Sub})$ & 1 & 0 \\
\hline 3(Sup) & 3 & 8 & 7(Sup) & 3 & 1 \\
\hline 3(Sub) & 2 & 6 & $7(\mathrm{Sub})$ & 2 & 0 \\
\hline 4(Sup) & 2 & 8 & 8(Sup) & 2 & 3 \\
\hline $4(\mathrm{Sub})$ & 2 & 0 & $8($ Sub $)$ & 2 & 3 \\
\hline
\end{tabular}

The maintenance unit is responsible for maintenance plans for a total of eight bridges under its jurisdiction in the next year. In this case, the planning period is set to 50 years. First, Table 6 illustrates the importance setting of the eight bridges. The larger the number, the more important the bridge.

Table 6. Data for bridge importance.

\begin{tabular}{cccc}
\hline Bridge No. & Importance & Bridge No. & Importance \\
\hline 1 & 1 & 5 & 2 \\
\hline 2 & 1 & 6 & 3 \\
\hline 3 & 1 & 7 & 3 \\
\hline 4 & 2 & 8 & 3 \\
\hline
\end{tabular}

\subsection{Validation of Model-I: Life Cycle Lifespan Evaluation Model}

Different maintenance techniques are sued for the eight bridges and they are divided into the categories: superstructures and substructures; therefore, their costs and maintenance periods are not 
the same. Table 7 shows the maintenance cost, maintenance period, and cost for keeping the effect period of the three maintenance plans for each bridge.

Table 7. Maintenance plan of case bridge.

\begin{tabular}{|c|c|c|c|c|c|}
\hline Facility & Plan & $\begin{array}{c}\text { Maintenance Cost } \\
\text { (Unit:10 Thousand NTD }\end{array}$ & $\begin{array}{l}\text { Maintenance Period } \\
\text { (Unit: Year) }\end{array}$ & $\begin{array}{l}\text { Cost of the Effect Period } \\
\text { (Unit: } 10 \text { Thousand NTD) }\end{array}$ & $\begin{array}{l}\text { Effect Period } \\
\text { (Unit: Year) }\end{array}$ \\
\hline \multirow{3}{*}{ 1(Sup) } & 1 (early) & \multirow{3}{*}{190} & \multirow{3}{*}{1} & \multirow{3}{*}{2} & 15 \\
\hline & 2(middle) & & & & 9 \\
\hline & 3(late) & & & & 7 \\
\hline \multirow{3}{*}{1 (sub) } & 1 (early) & \multirow{3}{*}{220} & \multirow{3}{*}{1} & \multirow{3}{*}{3} & 15 \\
\hline & 2(middle) & & & & 10 \\
\hline & 3(late) & & & & 8 \\
\hline \multirow{3}{*}{ 2(Sup) } & 1 (early) & \multirow{3}{*}{129} & \multirow{3}{*}{1} & \multirow{3}{*}{2} & 14 \\
\hline & 2(middle) & & & & 9 \\
\hline & 3(late) & & & & 6 \\
\hline \multirow{3}{*}{2 (sub) } & 1 (early) & \multirow{3}{*}{90} & \multirow{3}{*}{1} & \multirow{3}{*}{1} & 16 \\
\hline & 2(middle) & & & & 10 \\
\hline & 3(late) & & & & 7 \\
\hline \multirow{3}{*}{ 3(Sup) } & 1 (early) & \multirow{3}{*}{330} & \multirow{3}{*}{1} & \multirow{3}{*}{4} & 18 \\
\hline & 2(middle) & & & & 13 \\
\hline & 3(late) & & & & 10 \\
\hline \multirow{3}{*}{$3(\mathrm{sub})$} & 1 (early) & \multirow{3}{*}{345} & \multirow{3}{*}{1} & \multirow{3}{*}{4} & 20 \\
\hline & 2(middle) & & & & 16 \\
\hline & 3(late) & & & & 12 \\
\hline \multirow{3}{*}{ 4(Sup) } & 1 (early) & & & & 11 \\
\hline & 2(middle) & 116 & 1 & 2 & 8 \\
\hline & 3(late) & & & & 7 \\
\hline & 1 (early) & & & & 13 \\
\hline $4(\mathrm{sub})$ & 2(middle) & 174 & 1 & 2 & 10 \\
\hline & 3(late) & & & & 8 \\
\hline & 1 (early) & & & & 10 \\
\hline 5(Sup) & 2(middle) & 70 & 1 & 1 & 8 \\
\hline & 3(late) & & & & 7 \\
\hline & 1 (early) & & & & 9 \\
\hline 5 (sub) & 2(middle) & 110 & 1 & 2 & 7 \\
\hline & 3(late) & & & & 6 \\
\hline & 1 (early) & & & & 15 \\
\hline 6(Sup) & 2(middle) & 210 & 1 & 3 & 11 \\
\hline & 3(late) & & & & 8 \\
\hline & 1 (early) & & & & 16 \\
\hline $6(\mathrm{sub})$ & 2(middle) & 240 & 1 & 3 & 13 \\
\hline & 3(late) & & & & 10 \\
\hline & 1 (early) & & & & 11 \\
\hline 7(Sup) & 2(middle) & 100 & 1 & 1 & 9 \\
\hline & 3(late) & & & & 8 \\
\hline & 1 (early) & & & & 13 \\
\hline $7(\mathrm{sub})$ & 2(middle) & 100 & 1 & 1 & 11 \\
\hline & 3(late) & & & & 9 \\
\hline
\end{tabular}


Table 7. Cont.

\begin{tabular}{|c|c|c|c|c|c|}
\hline Facility & Plan & $\begin{array}{l}\text { Maintenance Cost } \\
\text { (Unit:10 Thousand NTD }\end{array}$ & $\begin{array}{l}\text { Maintenance Period } \\
\text { (Unit: Year) }\end{array}$ & $\begin{array}{l}\text { Cost of the Effect Period } \\
\text { (Unit: } 10 \text { Thousand NTD) }\end{array}$ & $\begin{array}{l}\text { Effect Period } \\
\text { (Unit: Year) }\end{array}$ \\
\hline \multirow{3}{*}{ 8(Sup) } & 1 (early) & & & & 14 \\
\hline & 2(middle) & 80 & 1 & 1 & 10 \\
\hline & 3(late) & & & & 8 \\
\hline \multirow{3}{*}{8 (sub) } & 1 (early) & & & & 15 \\
\hline & 2(middle) & 100 & 1 & 1 & 11 \\
\hline & 3(late) & & & & 10 \\
\hline
\end{tabular}

The influence matrix of plan selection for the bridges is shown in Table 8, which shows the influence of the selection of the predecessor and successor plans on the reduction in the effect period.

Table 8. Influence Matrix.

\begin{tabular}{ccc}
\hline Predecessor & Successor & Duration Lost (Year) \\
\hline \multirow{2}{*}{ 1(early plan) } & 1(early) & 4 \\
\cline { 2 - 3 } & 2(middle) & 3 \\
\cline { 2 - 3 } 2(middle plan) & 3(late) & 0 \\
\cline { 2 - 3 } & 2(early) & 3 \\
\hline \multirow{2}{*}{ 3(late plan) } & 3(late) & 1 \\
\cline { 2 - 3 } & 2(early) & 0 \\
\cline { 2 - 3 } & 3(late) & 2 \\
\hline
\end{tabular}

First, according to the requirements for budget planning outlined by subordinate agencies, the results shown in Table 9 and Figure 8 are obtained via calculations using Model-I. The content value is the selected plan. To make all facilities reach the plan cycle of 50 years, at most, eight rounds of maintenance are required. By comparing the optimized result of Model-I (Figure 8) with the simulation result of the practical maintenance decisions (Figure 9)-which are defined by the planner's experience (human-made maintenance decisions usually happen when the facility's condition is close to the minimal acceptable level) - it can be seen that the number of maintenance plans is more than that stated by the result of Model-I in the planning period. This means that the government is required to provide the funds for the increased maintenance cost. Moreover, there is no solution when the maintenance budget falls short, other than to take the required money out of another budget instead. Therefore, Model-I not only provides an economical solution but also a flexible way to face the real situation.

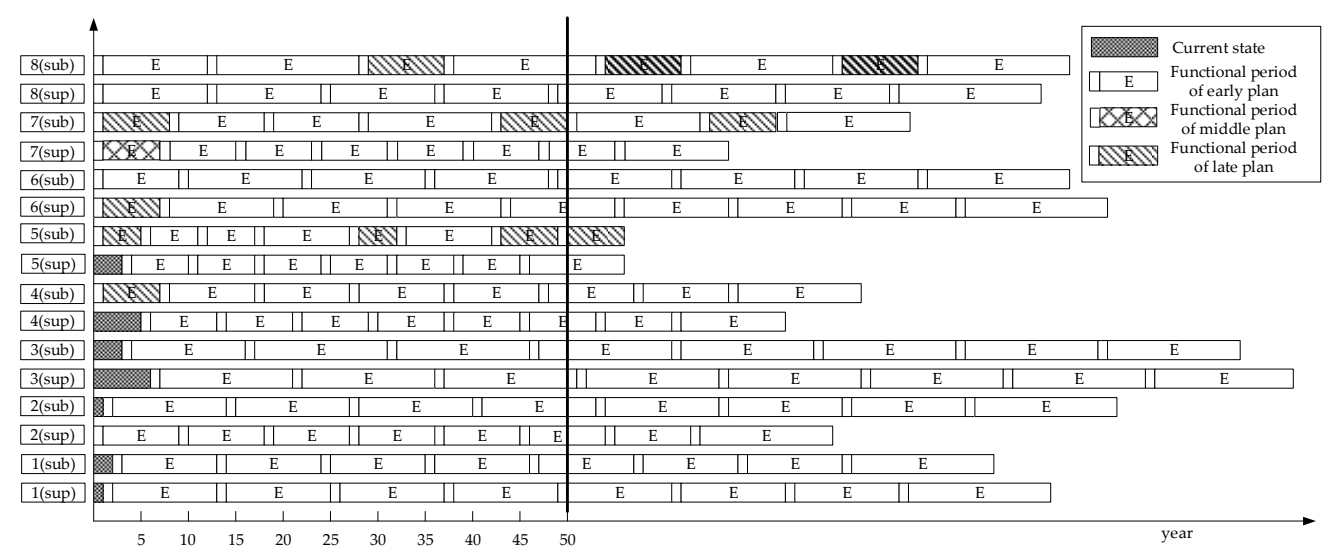

Figure 8. Gantt chart of Model-I results. 
Table 9. Calculation results of Model-I.

\begin{tabular}{lllllllll}
\hline \multicolumn{1}{l}{ Facility } & & & & & & & \\
\hline Period No. & $\mathbf{1}$ sup & $\mathbf{1}$ sub & 2 sup & 2 sub & 3 sup & 3 sub & 4 sup & 4 sub \\
\hline 1st period plan & 1 & 1 & 1 & 1 & 1 & 1 & 1 & 3 \\
\hline 2nd period plan & 1 & 1 & 1 & 1 & 1 & 1 & 1 & 1 \\
\hline 3rd period plan & 1 & 1 & 1 & 1 & 1 & 1 & 1 & 1 \\
\hline 4th period plan & 1 & 1 & 1 & 1 & 1 & 1 & 1 & 1 \\
\hline 5th period plan & 1 & 1 & 1 & 1 & 1 & 1 & 1 & 1 \\
\hline 6th period plan & 1 & 1 & 1 & 1 & 1 & 1 & 1 & 1 \\
\hline 7th period plan & 1 & 1 & 1 & 1 & 1 & 1 & 1 & 1 \\
\hline 8th period plan & 1 & 1 & 1 & 1 & 1 & 1 & 1 & 1 \\
\hline & Facility & & & & & & \\
\hline Period No. & $\mathbf{5}$ sup & $\mathbf{5}$ sub & $\mathbf{6}$ sup & $\mathbf{6}$ sub & $\mathbf{7}$ sup & $\mathbf{7}$ sub & $\mathbf{8}$ sup & $\mathbf{8}$ sub \\
\hline 1st period plan & 1 & 3 & 3 & 3 & 2 & 3 & 1 & 1 \\
\hline 2nd period plan & 1 & 1 & 1 & 1 & 1 & 1 & 1 & 1 \\
\hline 3rd period plan & 1 & 1 & 1 & 1 & 1 & 1 & 1 & 3 \\
\hline 4th period plan & 1 & 1 & 1 & 1 & 1 & 1 & 1 & 1 \\
\hline 5th period plan & 1 & 3 & 1 & 1 & 1 & 3 & 1 & 3 \\
\hline 6th period plan & 1 & 1 & 1 & 1 & 1 & 1 & 1 & 1 \\
\hline 7th period plan & 1 & 3 & 1 & 1 & 1 & 3 & 1 & 3 \\
\hline 8th period plan & 1 & 3 & 1 & 1 & 1 & 1 & 1 & 1 \\
\hline & & & & & & & & 1 \\
\hline
\end{tabular}

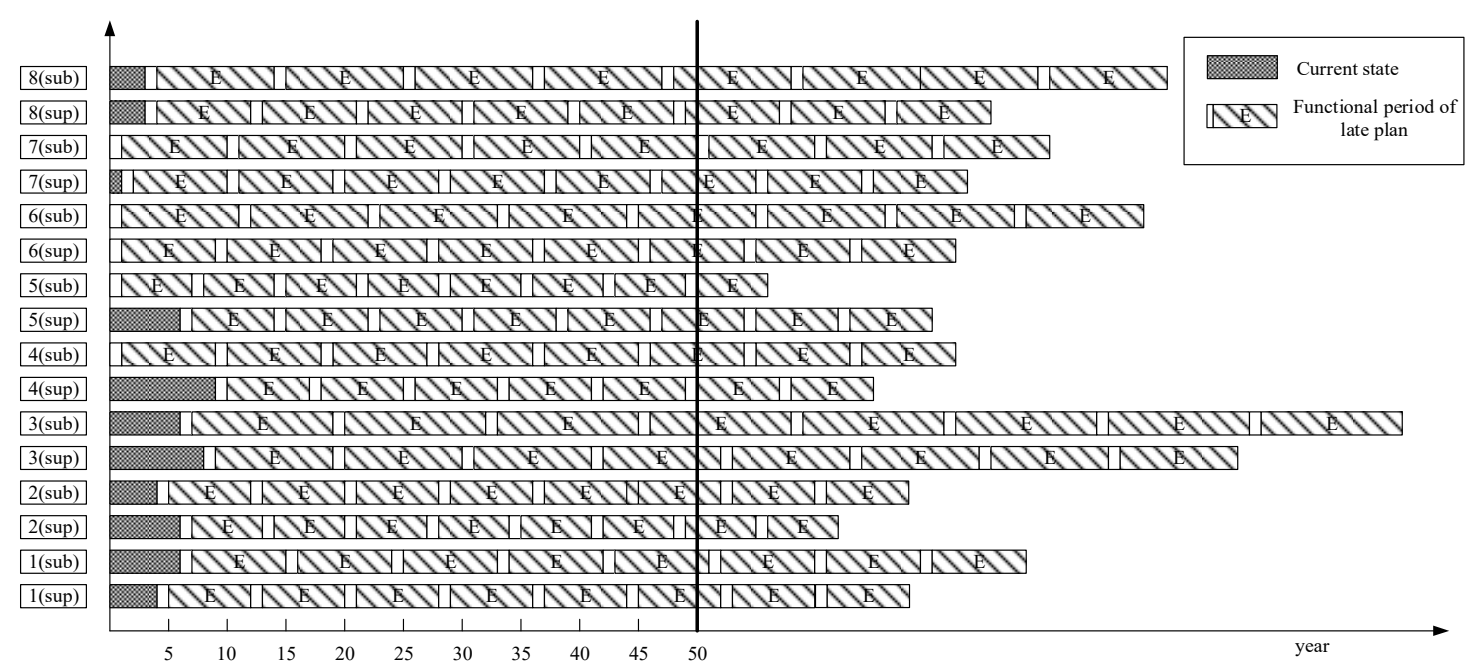

Figure 9. Simulation result of practical maintenance decisions.

Therefore, the effect period obtained by the selection of each plan from Model-I can be organized as shown in Table 10. 
Table 10. Calculation results of effect period.

\begin{tabular}{lllllllll}
\hline Facility & $\mathbf{1}$ sup & $\mathbf{1}$ sub & 2 sup & 2 sub & 3 sup & 3 sub & 4 sup & 4 sub \\
\hline Effect period(year) & 1 & 2 & 0 & 1 & 6 & 3 & 5 & 0 \\
\hline 1st period plan & 11 & 10 & 8 & 12 & 14 & 15 & 7 & 6 \\
\hline 2nd period plan & 11 & 10 & 8 & 12 & 14 & 15 & 7 & 9 \\
\hline 3rd period plan & 11 & 10 & 8 & 12 & 14 & 15 & 7 & 9 \\
\hline 4th period plan & 11 & 10 & 8 & 12 & 14 & 15 & 7 & 9 \\
\hline 5th period plan & 11 & 10 & 8 & 12 & 14 & 15 & 7 & 9 \\
\hline 6th period plan & 11 & 10 & 8 & 12 & 14 & 15 & 7 & 9 \\
\hline 7th period plan & 11 & 10 & 8 & 12 & 14 & 15 & 7 & 9 \\
\hline 8th period plan & 15 & 15 & 14 & 15 & 15 & 15 & 11 & 13 \\
\hline Facility & $\mathbf{5}$ sup & $\mathbf{5}$ sub & $\mathbf{6}$ sup & $\mathbf{6}$ sub & $\mathbf{7}$ sup & $\mathbf{7}$ sub & $\mathbf{8}$ sup & $\mathbf{8}$ sub \\
\hline Effect period(year) & 3 & 0 & 0 & 0 & 0 & 0 & 0 & 0 \\
\hline 1st period plan & 6 & 4 & 6 & 8 & 6 & 7 & 10 & 11 \\
\hline 2nd period plan & 6 & 5 & 11 & 12 & 7 & 9 & 10 & 15 \\
\hline 3rd period plan & 6 & 5 & 11 & 12 & 7 & 9 & 10 & 8 \\
\hline 4th period plan & 6 & 9 & 11 & 12 & 7 & 13 & 10 & 15 \\
\hline 5th period plan & 6 & 4 & 11 & 12 & 7 & 7 & 10 & 8 \\
\hline 6th period plan & 6 & 9 & 11 & 12 & 7 & 13 & 10 & 15 \\
\hline 7th period plan & 6 & 6 & 11 & 12 & 7 & 7 & 10 & 8 \\
\hline 8th period plan & 10 & 6 & 15 & 15 & 11 & 13 & 14 & 15 \\
\hline & & & & & & & & \\
\hline
\end{tabular}

When the budget is abundant, the most common choice of maintenance plan for bridges will be plan one (early maintenance), as this has the greatest benefit, i.e., the plan with the highest number of effect years, and will repeat it until the end of the plan cycle. In the results of Model-I, most bridges repeat the same plan until the end of the plan cycle, except for the first cycle. Such results show that, at the beginning of the plan cycle, because of the influence of the current situation data, Model-I will first choose the best plan to suit the current situation to obtain the maximum overall benefit. In addition, by comparing Table 9 with Table 10, it can be found that for the last cycle of the majority of bridges in the model, even if the same plan is selected, the maintenance period may be still different because all other cycles-except the last cycle-have subsequent operations. If there are no subsequent operations, then the effect period will not be reduced, owing to the selection of the subsequent plans. From Table 9, it can be observed that the selection of plans for some facilities is constantly changing, except at the initial stage of the plan cycle. There are several possible reasons for this situation. First, taking the substructure of bridge eight as an example, after selecting maintenance plan one at the initial stage of the plan cycle, although the plans selected in the subsequent maintenance cycles have changed, regularity can be seen, proving that in addition to the maximum benefits obtained by single plan selection, the combination of plans may also create greater benefits. Another possible reason is that, like the substructures of bridge five and bridge seven in their respective life cycles, they seem to change maintenance plans irregularly and continuously, which means that when calculating different plan combinations, Model-I may have some combinations with the same sum, but they can all be selected; therefore, irregular plan combinations may occur. 


\subsection{Validation of Model-II: Annual Budget Allocation Model}

From the results of Model-I, the budget value required for the first year can be calculated, totaling NTD 12.6 million (USD 420 thousand), as shown in Table 11 below. Letter M stands for maintenance and $\mathrm{E}$ for effect period:

Table 11. Budget demand for the first year.

\begin{tabular}{|c|c|c|c|c|c|c|c|c|}
\hline Facility & 1 sup & $1 \mathrm{sub}$ & 2 sup & $2 \mathrm{sub}$ & 3 sup & $3 \mathrm{sub}$ & 4 sup & $4 \mathrm{sub}$ \\
\hline state & $\mathrm{E}$ & $\mathrm{E}$ & M & $\mathrm{E}$ & E & E & M & $\mathrm{E}$ \\
\hline Cost * & 0.67 & 1 & 43 & 0.33 & 1.33 & 1.33 & 0.67 & 58 \\
\hline Facility & 5 sup & $5 \mathrm{sub}$ & 6 sup & $6 \mathrm{sub}$ & 7 sup & $7 \mathrm{sub}$ & 8 sup & $8 \mathrm{sub}$ \\
\hline state & $\mathrm{E}$ & $\mathrm{M}$ & $\mathrm{M}$ & M & M & $\mathrm{M}$ & M & $\mathrm{M}$ \\
\hline Cost* & 0.33 & 3.67 & 7 & 8 & 3.33 & 3.33 & 2.67 & 3.33 \\
\hline
\end{tabular}

Assuming that the actual budget is approved, and the amount of the actual budget is reduced to NTD 10 million, then the calculation results for Model-II will be the same as those shown in Table 12:

Table 12. Calculation results of Model-II.

\begin{tabular}{lllllllll}
\hline Facility & 1 sup & 1 sub & 2 sup & 2 sub & 3 sup & 3 sub & 4 sup & 4 sub \\
\hline Current plan & 2 & 2 & 1 & 2 & 3 & 2 & 2 & 2 \\
\hline 1st period plan & 1 & 1 & 3 & 1 & 1 & 2 & 1 & 3 \\
\hline Start time (year) & 1 & 2 & 6 & 1 & 6 & 5 & 5 & 0 \\
\hline 1st Effect period & 15 & 15 & 6 & 15 & 15 & 15 & 11 & 8 \\
\hline Facility & $\mathbf{5}$ sup & $\mathbf{5}$ sub & $\mathbf{6}$ sup & $\mathbf{6}$ sub & $\mathbf{7 ~ s u p ~}$ & $\mathbf{7}$ sub & $\mathbf{8 ~ s u p ~}$ & $\mathbf{8}$ sub \\
\hline Current plan & 2 & 3 & 1 & 1 & 3 & 2 & 2 & 2 \\
\hline 1st period plan & 1 & 3 & 3 & 3 & 3 & 3 & 1 & 2 \\
\hline Start time (year) & 3 & 0 & 0 & 0 & 1 & 0 & 0 & 2 \\
\hline 1st Effect period & 10 & 6 & 8 & 10 & 8 & 9 & 14 & 11 \\
\hline
\end{tabular}

It can be seen from the comparison between Tables 11 and 12, that the lack of an actual budget has caused some facilities to be unable to carry out maintenance work, as calculated using Model-I. Different maintenance plans have been chosen for a total of four facilities, two sup, seven sup, and eight sub, which should undergo maintenance. However, maintenance could not be carried out as scheduled due to an insufficient budget. Taking two sup as an example, the calculation results of Model-II show that the facility will continue to be used for 6 years before maintenance in plan three is carried out, and the effect period will be 6 years.

It is assumed in the study that all bridges are not allowed to be in an unusable state. Thus, when the annual maintenance budget is insufficient for the facilities to be maintained as originally planned, the maintenance will have to be delayed. If the budget for the next year is again insufficient, the calculation using Model-II will be carried out again, and those that cannot be maintained will also be delayed. When the maintenance cannot be delayed any more in a certain year, the model will have no solution. The failure to obtain a solution is not an optimization failure but reflects that the annual budget must be higher than a certain value so that all facilities can be maintained. The next section will analyze such a situation. 


\subsection{Sensitivity Analysis for Budget Limitation in Model-II}

To analyze the influence of the budget ceiling on the scheduling results in the budget evaluation model, this section conducts a sensitivity analysis on the budget ceiling for this case study. First, the budget is fine-tuned from NTD 12.6 million (USD 420 thousand) to NTD 12.59 million (USD 419.67 thousand), with the results shown in Tables 13 and 14.

Table 13. Plan selection impact of budget ceiling (from USD 420 thousand to USD 419.67 thousand).

\begin{tabular}{lllllllll}
\hline Facility & 1 sup & 1 sub & 2 sup & 2 sub & 3 sup & 3 sub & 4 sup & 4 sub \\
\hline 1st plan period & 1 & 1 & 1 & 1 & 1 & 1 & 1 & 3 \\
\hline 2nd plan period & 1 & 1 & 1 & 1 & 1 & 1 & 1 & 1 \\
\hline 3rd plan period & 1 & 1 & 1 & 1 & 1 & 1 & 1 & 1 \\
\hline 4th plan period & 1 & 1 & 1 & 1 & 1 & 1 & 1 & 1 \\
\hline 5th plan period & 1 & 1 & 1 & 1 & 1 & 1 & 1 & 1 \\
\hline 6th plan period & 1 & 1 & 1 & 1 & 1 & 1 & 1 & 1 \\
\hline 7th plan period & 1 & 1 & 1 & 1 & 1 & 1 & 1 & 1 \\
\hline 8th plan period & 1 & 1 & 1 & 1 & 1 & 1 & 1 & 1 \\
\hline Facility & $\mathbf{5}$ sup & $\mathbf{5}$ sub & $\mathbf{6}$ sup & $\mathbf{6}$ sub & $\mathbf{7}$ sup & $\mathbf{7}$ sub & $\mathbf{8}$ sup & $\mathbf{8}$ sub \\
\hline 1st plan period & 1 & 3 & 3 & 3 & 2 & 3 & 1 & 2 \\
\hline 2nd plan period & 1 & 1 & 1 & 1 & 1 & 1 & 1 & 1 \\
\hline 3rd plan period & 1 & 1 & 1 & 1 & 1 & 1 & 1 & 3 \\
\hline 4th plan period & 1 & 1 & 1 & 1 & 1 & 1 & 1 & 1 \\
\hline 5th plan period & 1 & 3 & 1 & 1 & 1 & 3 & 1 & 3 \\
\hline 6th plan period & 1 & 1 & 1 & 1 & 1 & 1 & 1 & 1 \\
\hline 7th plan period & 1 & 3 & 1 & 1 & 1 & 3 & 1 & 3 \\
\hline 8th plan period & 1 & 3 & 1 & 1 & 1 & 1 & 1 & 1 \\
\hline
\end{tabular}

Table 14. Current status impact of budget ceiling (from USD 420 thousand to USD 419.67 thousand).

\begin{tabular}{|c|c|c|c|c|c|c|c|c|}
\hline Facility & 1 sup & $1 \mathrm{sub}$ & 2 sup & $2 \mathrm{sub}$ & 3 sup & $3 \mathrm{sub}$ & 4 sup & $4 \mathrm{sub}$ \\
\hline Period & $\mathrm{E}$ & $\mathrm{E}$ & M & $\mathrm{E}$ & E & $\mathrm{E}$ & $\mathrm{E}$ & M \\
\hline Cost of the period * & 0.67 & 1 & 43 & 0.33 & 1.33 & 1.33 & 0.67 & 58 \\
\hline $\begin{array}{l}\text { Years remaining of } \\
\text { effect period }\end{array}$ & 1 & 2 & 0 & 1 & 6 & 3 & 5 & 0 \\
\hline Facility & 5 sup & $5 \mathrm{sub}$ & 6 sup & $6 \mathrm{sub}$ & 7 sup & $7 \mathrm{sub}$ & 8 sup & $8 \mathrm{sub}$ \\
\hline Period & $\mathrm{E}$ & M & M & M & M & M & M & $\mathrm{E}$ \\
\hline Cost of the period * & 0.33 & 36.67 & 70 & 80 & 33.33 & 33.33 & 26.67 & 0.33 \\
\hline $\begin{array}{l}\text { Years remaining of } \\
\text { effect period }\end{array}$ & 3 & 0 & 0 & 0 & 0 & 0 & 0 & 2 \\
\hline
\end{tabular}

* Unit: 1 thousand (USD).

The slight reduction in the budget can still keep all the facilities in working condition during the plan cycle. However, the superstructure of bridge eight cannot undergo maintenance operation in the first year due to the insufficient annual budget; thus, maintenance will have to be postponed. The new result is to change the plan selection to the middle plan and act during the third year, as shown in Tables 13 and 14. 
From Table 15, when the budget ceiling is gradually adjusted to NTD 11.6 million (USD 386.670), maintenance for the superstructure of bridge eight will have to be postponed due to the gradual reduction in the budget. The plan changes to the middle plan in the first plan period there is a delay of 2 years.

Table 15. Plan selection impact of budget ceiling variation (1st plan period) compared with base budget USD 420,000.

\begin{tabular}{ccccc}
\hline \multirow{2}{*}{ Facility } & \multicolumn{4}{c}{ Budget Ceiling } \\
\cline { 2 - 5 } & USD $\mathbf{4 2 0 , 0 0 0}$ & USD $\mathbf{4 1 9 , 6 7 0}$ & USD 386,670 & USD 353,670 \\
\hline 1sup & 1 & 1 & 1 & 1 \\
1sub & 1 & 1 & 1 & 1 \\
2sup & 1 & 1 & 1 & 1 \\
2sub & 1 & 1 & 1 & 1 \\
3sup & 1 & 1 & 1 & 1 \\
3sub & 1 & 1 & 1 & 1 \\
4sup & 1 & 1 & 1 & 1 \\
4sub & 3 & 3 & 3 & 3 \\
5sup & 1 & 1 & 1 & 1 \\
5sub & 3 & 3 & 3 & 3 \\
6sup & 3 & 3 & 3 & 3 \\
6sub & 3 & 3 & 3 & 3 \\
7sup & 2 & 2 & 2 & 3 \\
7sub & 3 & 3 & 3 & 2 \\
8sup & 1 & 1 & 2 & 2 \\
8sub & 1 & 2 & 2 & 3 \\
\hline
\end{tabular}

Continuously, when the budget ceiling is down to NTD 10.61 million (USD 353,670), the superstructure of bridge seven must be postponed.

Until the budget ceiling is adjusted to NTD 8.55 million (USD 285,000), there is no solution to the model, indicating that the budget value must be at least more than NTD 8.56 million (USD 285,330) if all facilities are to remain in an effect condition.

\section{Conclusions}

From the perspective of life cycle, bridges require reasonable maintenance plans, which are submitted to the higher authorities for approval. However, it is usually impossible to obtain the full amount of the requested budget; thus, rearrangement of maintenance plans is often required. Due to the cyclic occurrence of such facts, it is important to have an appropriate adjustment mechanism for maintenance scheduling to ensure the long-term safety of bridges. Therefore, this study adopts the concept of resource-constrained scheduling in terms of RCPSP to develop a two-stage optimization model. Model-I evaluates how to keep all facilities in working condition throughout the plan cycle, and maximize the overall lifespan. After the actual annual budget is approved, Model-II will respond to the maintenance plan adjustment due to the difference between the planned and approved budget. Thereafter, new parameters are re-entered for Model-I according to the actual data of current bridge status. Thus, given the strength of the RCPSP framework, the two-stage model can be used repeatedly and alternately, to generate good solutions to address the life cycle maintenance scheduling problems in terms of bridge infrastructures. In practice, it can also provide good flexibility to respond to changes in the status quo and unexpected situations, such as the tremendous decrease in service level as a consequence of natural disasters.

Considering the benefits of in-advance maintenance actions, this study proposes three plans, namely, early, middle, and late maintenance plans, based on the maintenance time point. From the case study analysis, the earlier the maintenance is carried out, the greater the resulting benefits will be, while the benefits of late maintenance will be less. However, choosing the early maintenance 
plan indicates that more of the effect period time of the preceding plan will be sacrificed, with the opposite being true for the late maintenance plan. Therefore, different combination effects will be produced depending on the different predecessor and successor plans. Such combination effects will influence the overall plan cycle. Furthermore, this study analyzes and verifies the results through case study. The optimization results show that the proposed two-stage model reflects the existing data and provides management personnel with appropriate maintenance plans. It can be concluded that Model-I will adjust the first period plan according to the current situation of the bridges to achieve the maximum benefits. Moreover, it can be observed from the local regulation perspective, in addition to the maximum benefits obtained from the selection of a single plan, that a combination of plans may also create greater benefits. Through parameter refinement of Model-II, the optimized results obtained from Model-II reasonably adjusts the maintenance plan until there is no solution, further providing management personnel with an understanding of the minimum budget requirement for the current year.

Future work can extend current research results to integrate post-disaster emergency repairs, that are excluded from this study, into the Model-II formulation. Such extension in the RCPSP framework will involve the addition of new emergency activities to the current activity network of life cycle maintenance works, with the input of an additional budget and new assessment on the status of damaged bridges. Moreover, the concept of bridge life cycle management in Taiwan's public sector is still in the preliminary stage, and the historical data for bridge maintenance issues are difficult to collect in a systematic way. Therefore, some crucial data, such as the effect period and years remaining of the effect period, were collected through interviews with experts. Once all the required bridge data, including related environmental factors, can be stored in a centralized database, the automated assessment of important data regarding bridge maintenance then will be realized through a normalized analysis, and proven by scientific measures.

Author Contributions: Conceptualization, S.-S.L.; methodology, S.-S.L.; validation, S.-S.L. and H.-Y.H.; formal analysis, S.-S.L.; resources, S.-S.L.; writing—original draft preparation, S.-S.L., H.-Y.H.; writing—review and editing, S.-S.L. and N.R.D.K.; project administration, S.-S.L. All authors have read and agreed to the published version of the manuscript.

Funding: This research received no external funding.

Conflicts of Interest: The authors declare no conflict of interest.

\section{References}

1. McDaniel, M.; Celaya, M.; Nazarian, M. Concrete bridgedeck quality mapping with seismic methods: Case study in Texas. Transp. Res. Rec. 2010, 2202, 53-60. [CrossRef]

2. Ghodoosi, F.; Samra, S.A.; Zeynalian, M.; Zayed, T. Maintenance Cost Optimization for Bridge Structures Using System Reliability Analysis and Genetic Algorithms. J. Constr. Eng. Manag. 2018, 144, 1-10. [CrossRef]

3. Zhang, Y.; Kim, C.-W.; Tee, K.F.; Lam, J. Optimal sustainable life cycle maintenance strategies for port infrastructures. J. Clean. Prod. 2017, 1693-1709. [CrossRef]

4. Daneshkhah, A.; Stocksc, N.; Jeffrey, P. Probabilistic sensitivity analysis of optimised preventive maintenance strategies for deteriorating infrastructure assets. Reliab. Eng. Syst. Saf. 2017, 33-45. [CrossRef]

5. Xie, H.-B.; Wu, W.-J.; Wang, Y.-F. Life-time reliability based optimization of bridge maintenance strategy considering LCA and LCC. J. Clean. Prod. 2018, 176, 36-45. [CrossRef]

6. Saydam, D.; Frangopol, D.M. Risk-Based Maintenance Optimization of deteriorating Bridges. Struct. Eng. 2015, 141, 04014120. [CrossRef]

7. Fang, Y.; Sun, L. Developing A Semi-Markov Process Model for Bridge Deterioration Prediction in Shanghai. Sustainability 2019, 11, 5524. [CrossRef]

8. Lwambuka, L.; Mtenga, P.V. Bridge Management Strategy Based on Extreme User Costs for Bridge Network Condition. Adv. Civ. Eng. 2014, 2014, 390359. [CrossRef]

9. Lazarev, A.A.; Grishin, E.M.; Galakhov, S.A.; Tarasov, G.V. Algorithms for locomotives maintenance schedule. IFAC Pap. 2019, 52, 951-956. [CrossRef] 
10. Cheng, M.Y.; Tram, D.H.; Wu, Y.W. Using a fuzzy clustering chaotic-based differential evolution with serial method to solve resource-constrained project scheduling problems. Autom. Constr. 2014, 37, 88-97. [CrossRef]

11. Liu, J.; Liu, Y.; Shi, Y.; Li, J. Solving Resource-Constrained Project Scheduling Problem via Genetic Algorithm. J. Comput. Civ. Eng. 2020, 34. [CrossRef]

12. Bettemir, Ö.; Sonmez, R.R.-C. Hybrid genetic algorithm with simulated annealing for resource-constrained project scheduling. J. Manag. Eng. 2014, 31, 04014082. [CrossRef]

13. IBM ILOG CPLEX Optimization Studio. Available online: https://www.ibm.com/products/ilog-cplexoptimization-studio/details (accessed on 15 October 2020).

14. Durazo-Cardenas, I.; Starr, A.; Turner, C.; Tiwari, A.; Kirkwood, L.; Bevilacqua, M.; Xu, Y.E. An autonomous system for maintenance complex infrastructure: Fusing the railways' condition, planning scheduling data-rich and cost. Transp. Res. Part C 2018, 89, 234-253. [CrossRef]

15. Kumar, R.; Cline, D.; Gardoni, P. A Stochastic Framework to Model Deterioration in Engineering Systems. Struct. Saf. 2015, 53, 36-43. [CrossRef]

16. Su, Z.; Jamshidi, A.; Núñez, A.; Baldi, S.; Schutter, B. Multi-level condition-based maintenance planning for railway infrastructures-A scenario-based chance-constrained approach. Transp. Res. Part C 2017, 1693-1709. [CrossRef]

17. Sabatino, S.; Frangopol, D.M.; Dong, Y. Sustainability-informed maintenance optimization of highway bridges considering multi-attribute utility and risk attitude. Eng. Struct. 2015, 310-321. [CrossRef]

18. Srinivasan, R.; Parlikad, A.K. Value of condition monitoring infrastructure maintenance. Comput. Ind. Eng. 2013, 66, 233-241. [CrossRef]

19. Stajano, F.; Hoult, N.; Wassell, I.; Bennett, P.; Middleton, C.; Soga, K. Smart bridges, smart tunnels: Transforming wireless sensor networks from research prototypes into robust engineering infrastructure. Ad Hoc Netw. 2010, 8, 872-888. [CrossRef]

20. Liden, T.; Joborn, M. Dimensioning windows for railway infrastructure maintenance: Cost efficiency versus traffic impact. J. Rail Transp. Plan. Manag. 2016, 6, 32-47. [CrossRef]

21. Lu, J.-Y.; Hong, J.-H.; Su, C.-C.; Wang, C.-Y.; Lai, J.-S. Field Measurements and Simulation of Bridge Scour Depth Variations during Floods. J. Hydraul. Eng. 2008, 134, 810-821. [CrossRef]

22. Feng, C.-W.; Ju, S.-H.; Huang, H.-Y. Using a Simple Soil Spring Model and Support Vector Machine to Determine Bridge Scour Depth and Bridge Safety. J. Perform. Constr. Facil. 2016, 30, 1-14. [CrossRef]

23. Odolinski, K.; Wheat, P. Dynamics in rail infrastructure provision: Maintenance and renewal costs in Sweden. Econ. Transp. 2018, 14, 21-30. [CrossRef]

24. Contreras-Nieto, C.; Shan, Y.; Lewis, P.; Hartel, J.A. Bridge Maintenance prioritization using analytic hierarchy process and fusion tables. Autom. Constr. 2019, 101, 99-110. [CrossRef]

25. Alberto, M.; Simoes, L.; Negrao, J. Optimization of concrete cable-stayed bridges under seismic action. Comput. Struct. 2019, 222, 36-47. [CrossRef]

26. Xie, Y.; Zhang, J. Design and optimization of seismic isolation and damping for highway bridges based on probabilistic repair cost ratio. J. Struct. Eng. 2018, 144, 04018125. [CrossRef]

27. Orcesi, A.D.; Frangopol, D.M. Optimization of bridge maintenance strategies based on structural health monitoring information. Struct. Saf. 2011, 33, 26-41. [CrossRef]

28. Silva, M.S.; Frangopol, D.M.; Padgett, J.; Soliman, M. Maintenance and Operation of Infrastructure Systems: Review. J. Struct. Eng. 2016, 142, F4016004. [CrossRef]

29. Ghodoosi, F.; Bagchi, A.; Zayed, T. System-Level Deterioration Model for Reinforced Concrete Bridge Decks. J. Bridge. Eng. 2015, 20, 04014081. [CrossRef]

30. Garavaglia, E.; Sgambi, L. Selective maintenance planning of a steel truss bridge based on the Markovian approach. Eng. Struct. 2016, 125, 532-545. [CrossRef]

31. Wu, D.; Yuan, C.; Wesley, K.; Liu, H. A life-cycle optimization model using semi-markov process for highway bridge maintenance. Appl. Math. Model. 2017, 43, 45-60. [CrossRef]

32. Yang, D.Y.; Frangopol, D.M.; Ten, J.-G. Probabilistic life-cycle optimization of durability-enhancing maintenance actions: Application to FRP strengthening planning. Eng. Struct. 2019, 188, 340-349. [CrossRef]

33. Choi, Y.; Lee, J.; Kong, J. Performance Degradation Model for Concrete Deck of Bridge Using Pseudo-LSTM. Sustainability 2020, 12, 3848. [CrossRef] 
34. Calvert, G.; Neves, L.; Andrews, J.; Hamer, M. Modelling interactions between multiple bridge deterioration mechanisms. Eng. Struct. 2020, 221, 111059. [CrossRef]

35. Orcesi, A.D.; Cremona, C.F. A bridge network maintenance framework for Pareto optimization of stakeholders/users costs. Reliab. Eng. Syst. Saf. 2010, 95, 1230-1243. [CrossRef]

36. Thompson, P.D.; Soares, R.; Choung, H.J.; Najafi, F.T.; Kerr, R. User Cost Model for Bridge Management Systems. J. Transp. Res. Board 2010, 1697, 6-13. [CrossRef]

37. Huang, Y.-H.; Huang, H.-Y. A model for concurrent maintenance of bridge elements. Autom. Constr. 2012, 21, 74-80. [CrossRef]

38. Hu, X.; Daganzo, C.; Madanat, S. A reliability-based optimization scheme for maintenance management in large-scale bridge networks. Transp. Res. Part C Emerg. Technol. 2015, 55, 166-178. [CrossRef]

39. Frangopol, D.M.; Soliman, M. Life-cycle of structural systems: Recent achievements and future directions. Struct. Infrastruct. Eng. 2015, 12, 1-20. [CrossRef]

40. Borning, A. Principles and Practice of Constraint Programming. In Second International Workshop, PPCP '94; Rosario: Orcas Island, WA, USA, 1994.

41. Garey, M.R.; Johnson, D.S. Computers and Intractability: A Guide to the Theory of NP-completeness; W.H. Freeman \& Co.: New York, NY, USA, 1979.

42. Liu, S.-S.; Wang, C.-J. Optimizing linear project scheduling with multi-skilled crews. Autom. Constr. 2012, 24, 16-23. [CrossRef]

43. Meng, L.; Zhang, C.; Ren, Y.; Zhang, B.; Lv, C. Mixed-integer linear programming and constraint programming formulations for solving distributed flexible job shop scheduling problem. Comput. Ind. Eng. 2019, 142, 106347. [CrossRef]

44. Lunardi, W.; Birgin, E.; Laborie, P.; Ronconi, D.; Voos, H. Mixed Integer linear programming and constraint programming models for the online printing shop scheduling problem. Comput. Oper. Res. 2020, 123, 105020. [CrossRef]

45. Pour, S.M.; Drake, J.H.; Ejlertsen, L.S.; Rasmussen, K.A.; Burke, E.K. A hybrid constraint programming/ mixed integer programming framework for the preventive signaling maintenance crew scheduling problem. Eur. J. Oper. Res. 2018, 269, 341-352. [CrossRef]

46. Hauder, V.A.; Beham, A.; Raggl, S.; Parragh, S.N.; Affenzeller, M. Resource-constrained multi-project scheduling with activity and time flexibility. Comput. Ind. Eng. 2020, 150, 106857. [CrossRef]

47. Wallace, M.; Smith, N.Y. A new constraint programming model and solving for the cyclic hoist scheduling problem. Constraints 2020. [CrossRef]

48. Hojabri, H.; Gendreau, M.; Potvin, J.-Y.; Rousseau, L.-M. Large neighborhood search with constraint programming for a vehicle routing problem with synchronization constraints. Comput. Oper. Res. 2018, 92,87-97. [CrossRef]

49. Kizilay, D.; Hentenryck, P.; Eliiyi, D. Constraint programming models for integrated container terminal operations. Eur. J. Oper. Res. 2020, 286, 945-962. [CrossRef]

50. Herroelen, W.; Leus, R. Identification and illumination of popular misconceptions about project scheduling and time buffering in a resource-constrained environment. J. Oper. Res. Soc. 2017, 56, 102-109. [CrossRef]

51. Wang, T.; Abdallah, M.; Clevenger, C.; Monghasemi, S. Time-cost-quality trade-off analysis for planning construction projects. Eng. Constr. Archit. Manag. 2019. [CrossRef]

52. Banihashemi, S.A.; Khalilzadeh, M. Time-cost-quality-environmental impact trade-off resource constrained problem with DEA approach. Eng. Constr. Archit. Manag. 2020. [CrossRef]

53. Liu, S.-S.; Wang, C.-J. Resource-constrained construction project scheduling model for profit maximization considering cash flow. Autom. Constr. 2008, 17, 966-974. [CrossRef]

54. Goncalves, J.F.; Mendes, J.J.M.; Resende, M.G.C. A genetic algorithm for the resource constrained multi-project scheduling problem. Eur. J. Oper. Res. 2008, 189, 1171-1190. [CrossRef]

55. Hu, J.; Flood, I. Multi-objective Scheduling Model for Solving the Resource-constrained Project Scheduling and Resource Leveling Problems. In Proceedings of the ASCE International Conference on Computing in Civil. Engineering, Clearwater Beach, FL, USA, 17-20 June 2012; pp. 17-20. [CrossRef]

56. Elsayed, S.; Sarker, R.; Ray, T.; Coello, C. Consolidated optimization algorithm for resource- constrained project scheduling problem. Inf. Sci. 2017, 418-419, 346-362. [CrossRef]

57. Frühwirth, T.W.; Abdennadher, S. Essentials of Constraint Programming, 1st ed.; Springer: Berlin, Germany, 2003. 
58. Heipcke, S. Comparing constraint programming and mathematical programming approaches to discrete optimization-The change problem. J. Oper. Res. Soc. Jpn. 1999, 50, 581-595. [CrossRef]

59. Apt, K.R. Principles of Constraint Programming, 1st ed.; Cambridge University Press: Cambridge, UK, 2003.

60. Barták, R. Constraint programming: In pursuit of the holy grail. In Proceedings of the Week of Doctoral Students (WDS99), Prague, Czech Republic, 22-25 June 1999; pp. 555-564.

Publisher's Note: MDPI stays neutral with regard to jurisdictional claims in published maps and institutional affiliations.

(C) 2020 by the authors. Licensee MDPI, Basel, Switzerland. This article is an open access article distributed under the terms and conditions of the Creative Commons Attribution (CC BY) license (http://creativecommons.org/licenses/by/4.0/). 